\title{
Combination of Ad-SGE-REIC and Bevacizumab Modulates Glioma Progression by Suppressing Invasion and Angiogenesis
}

\section{Yasuhiko Hattori}

Okayama University

Kazuhiko Kurozumi ( $\nabla$ kurozu20@hama-med.ac.jp )

Hamamatsu University School of Medicine

Yoshihiro Otani

Okayama University

Atsuhito Uneda

Okayama University

Nobushige Tsuboi

Okayama University

\section{Kentaro Fujii}

Okayama University

Yusuke Tomita

Okayama University

\section{Tetsuo Oka}

Okayama University

Yuji Matsumoto

Okayama University

Yosuke Shimazu

Okayama University

Hiroyuki Michiue

Okayama University

Hiromi Kumon

Okayama University

Isao Date

Okayama University

\section{Research Article}

Keywords: glioma, invasion, angiogenesis, bevacizumab, Ad-SGE-REIC 
Posted Date: March 15th, 2021

DOl: https://doi.org/10.21203/rs.3.rs-285734/v1

License: (c) (i) This work is licensed under a Creative Commons Attribution 4.0 International License. Read Full License 


\section{Combination of Ad-SGE-REIC and bevacizumab modulates glioma progression by suppressing invasion and angiogenesis}

Yasuhiko Hattori ${ }^{1}$, Kazuhiko Kurozumi $^{2}$, Yoshihiro Otani $^{1)}$, Atsuhito Uneda ${ }^{1}$, Nobushige Tsuboi $^{1)}$, Kentaro Fujii ${ }^{1}$, Yusuke Tomita ${ }^{1)}$, Tetsuo Oka ${ }^{1}$, Yuji Matsumoto ${ }^{1}$, Yosuke Shimazu ${ }^{1)}$, Hiroyuki Michiue ${ }^{3)}$, Hiromi Kumon ${ }^{4)}$, Isao Date ${ }^{1)}$

1) Department of Neurological Surgery, Okayama University Graduate School of Medicine, Dentistry and Pharmaceutical Sciences, Okayama, Japan

2) Department of Neurosurgery, Hamamatsu University School of Medicine, Shizuoka, Japan

3) Neutron Therapy Research Center, Okayama University, Okayama, Japan

4) Innovation Center Okayama for Nanobio-targeted Therapy, Okayama University, Okayama, Japan

Correspondence should be addressed to K.K. (kurozu20@hama-med.ac.jp)

Corresponding Author: Kazuhiko Kurozumi

Address: Department of Neurosurgery, Hamamatsu University School of Medicine, 1-20-1

Handayama, Higashi-ku, Hamamatsu city, Shizuoka, Japan, 431-3192

Phone: +81-53-435-2281, Fax: +81-53-435-2282

E-mail: kurozu20@hama-med.ac.jp

\section{Running title}

Combined therapy of Ad-SGE-REIC with bevacizumab 


\begin{abstract}
Reduced expression in immortalized cells/Dickkopf-3 (REIC/Dkk-3) is a tumor suppressor and its overexpression has been shown to exert anti-tumor effects as a therapeutic target gene in many human cancers. Recently, we demonstrated the anti-glioma effects of an adenoviral vector carrying REIC/Dkk-3 with the super gene expression system (Ad-SGE-REIC). Anti-vascular endothelial growth factor treatments such as bevacizumab have demonstrated convincing therapeutic advantage in patients with glioblastoma. However, bevacizumab could not improve overall survival in patients with newly diagnosed glioblastoma. In this study, we examined the effects of Ad-SGE-REIC on glioma treated with bevacizumab. Treatment of Ad-SGE-REIC resulted in significant reduced numbers of invasion cells treated with bevacizumab.. Western blot analyses revealed increased expression of several endoplasmic reticulum stress markers in cells treated with both bevacizumab and Ad-SGE-REIC and decreased $\beta$-catenin protein levels. Expressions of apoptosis markers were also increased in cells with combination therapy. In malignant glioma mouse models, overall survival was extended in the combination therapy group. These results suggest that the combination therapy of Ad-SGE-REIC and bevacizumab exerts anti-glioma effects by suppressing angiogenesis and invasion of tumors. Combined AdSGE-REIC and bevacizumab might indicate a promising strategy for the treatment of malignant glioma.
\end{abstract}

Keywords: glioma, invasion, angiogenesis, bevacizumab, Ad-SGE-REIC 
Glioma is the most common type of primary brain tumor, and malignant gliomas are aggressive intracranial neoplasms in humans ${ }^{1,2}$. The characters are proliferation, angiogenesis, and invasion. Effective chemotherapeutic or molecular-targeted agents for malignant glioma have yet to be developed. Owing to the high resistance of malignant glioma to current therapies, new therapeutic agents are needed immediately.

Several clinical trials have investigated the efficacy of molecular targeted drugs in glioma ${ }^{3,4}$. Bevacizumab, an anti-vascular endothelial growth factor (VEGF) antibody, showed promising effects for the treatment of recurrent glioblastoma patients in trials ${ }^{5-7}$. However, the phase III AVAglio and RTOG 0825 studies did not show a statistically significant prolongation in overall survival in glioblastoma patients treated with bevacizumab ${ }^{8,9}$. In addition, Piao et al. found that anti-VEGF therapy made gliomas more resistant, invasive and aggressive and enhanced epithelial-to-mesenchymal transition ${ }^{10}$. In our previous research, we demonstrated that increased glioma cell invasion due to anti-VEGF therapy was associated with extracellular matrix changes, and an integrin inhibitor (cilengitide) reduced anti-VEGF therapy-induced glioma cell invasion ${ }^{11}$. We also showed that fibroblast growth factor 13 and delta-catenin regulate glioma cell invasion and are important for bevacizumab-induced glioma invasion ${ }^{12,13}$. Expression of the gene encoding reduced expression in immortalized cells/Dickkopf-3 (REIC/Dkk-3) was shown to be decreased in various human tumors ${ }^{14-17}$. The adenovirus REIC vector with the super gene expression system (Ad-SGE-REIC) was developed to overexpress REIC/Dkk-3 and showed in vitro and in vivo anti-cancer effects of Ad-SGE-REIC on malignant glioma ${ }^{18}$ and a Good Manufacturing Practice product of Ad-SGE-REIC was developed. After consultations with Pharmaceuticals and Medical Devices Agency (PMDA), we submitted a clinical trial notification for a phase I/IIa study of Ad-SGE-REIC for the treatment of recurrent malignant brain tumors in April 2019.

In this study, we evaluated the combination treatment of Ad-SGE-REIC and bevacizumab on glioma. Bevacizumab suppressed tumor angiogenesis, and Ad-SGE-REIC reduced 
bevacizumab-induced glioma invasion. We also observed decreased activation of the $\beta$-catenin signaling pathways in glioma cells treated with combined Ad-SGE-REIC and bevacizumab.

\section{RESULTS}

\section{Cytotoxic effect of combination therapy with bevacizumab and Ad-SGE-REIC}

Glioma cell lines (U87 $\mathrm{EGFR}$ and U251MG) and glioma stem cells (MGG8 and MGG23 cells) were incubated with bevacizumab and Ad-SGE-REIC, alone or in combination. Treatment of U87 $\triangle E$ EFR and U251MG cells with Ad-SGE-REIC decreased cell viability compared with controls in a time-dependent manner (Figure 1A, B), with a significant decrease in viability of cells treated with Ad-SGE-REIC compared with controls after $72 \mathrm{~h}$ (U87 $\triangle \mathrm{EGFR}, \mathrm{p}<0.05$; U251MG, $\mathrm{p}<0.001)$. After treatment with Ad-SGE-REIC, U87 $\triangle E$ EFR cells aggregated and floated from the dishes, whereas MGG8 and MGG23 cells were dissociated and adhered to the dishes (Figure 1C, D). There was a significant decrease in viability of MGG8 and MGG23 cells treated with Ad-SGE-REIC compared with PBS at 10 days $(\mathrm{MGG} 2, \mathrm{p}<0.05$; MGG8, $<<0.001)$ (Figure 1E, F). Bevacizumab had no cytotoxic effect against glioma cells and did not impact the cytotoxicity of Ad-SGE-REIC against glioma cells.

\section{Anti-angiogenic effect of bevacizumab in combination treatment}

To investigate the anti-angiogenic effect of bevacizumab, tube formation assays were performed using HUVECs. When HUVECs were cultured in the presence of VEGF, efficient tube formation was observed (Figure 2A, B). Treatment with bevacizumab efficiently inhibited tube formation compared with controls. In contrast, Ad-SGE-REIC conditioned medium (CM) increased the tube length in HUVECs. Notably, co-treatment of bevacizumab with Ad-SGEREIC (CM) significantly decreased tube length compared with HUVECs only treated with AdSGE-REIC (CM) (Ad-SGE-REIC and bevacizumab combination: $8.4 \times 10^{3} \pm 2.1 \times 10^{2}$ pixels vs. Ad-SGE-REIC, $1.3 \times 10^{3} \pm 1.3 \times 10^{2}$ pixels, $\mathrm{p}<0.009$; and vs. bevacizumab, $1.4 \times 10^{3} \pm 3.5 \times$ 
$10^{2}$ pixels, $\left.\mathrm{p}=0.028\right)$.

\section{Ad-SGE-REIC-infected glioma cells showed inhibited invasion activity in vitro}

We next examined the effects of bevacizumab and Ad-SGE-REIC on glioma cell invasion. The $\mathrm{CM}$ of malignant glioma cells infected by Ad-SGE-REIC was centrifuged and filtrated to eliminate virus and cell debris. The expression of REIC was detected by western blotting in AdSGE-REIC-infected glioma cells but not in Ad-SGE-REIC-infected glioma cells. Glioma cells treated with bevacizumab and/or Ad-SGE-REIC were seeded into upper chambers, and then cells invading through the membrane were counted after $24 \mathrm{~h}$ (Figure 2C). REIC significantly reduced the number of invading cells of U87 $\mathrm{EGFR}, \mathrm{U} 251 \mathrm{MG}$, and U87MG cell lines compared with controls (Figure 2D). Furthermore, the numbers of invading cells treated with bevacizumab were reduced by co-treatment with REIC.

\section{ER stress and $\beta$-catenin degradation by combination of REIC/Dkk-3 and bevacizumab in}

\section{glioma cells}

Western blot analysis revealed increased expressions of ER stress marker molecules Bip and phosphorylated IRE1 $\alpha$ in U87 $\triangle$ EGFR, U251 and MGG23 cells treated with the combination treatment compared with cells treated with either Ad-SGE-REIC or bevacizumab and control cells (Fig. 3A).

The Wnt signaling pathway regulates cell invasion by inhibition of proteasome-dependent proteolysis of $\beta$-catenin. Therefore, we evaluated the impact of the Ad-SGE-REIC and bevacizumab combination treatment on $\beta$-catenin expression in glioma cells (Fig. 3B). The results showed that $\beta$-catenin protein levels were more potently reduced by the combination treatment compared with levels in cells treated with Ad-SGE-REIC or bevacizumab as well as controls. 
Anti-tumor effect of combination therapy with bevacizumab and Ad-SGE-REIC in xenograft mice

We evaluated the potential antitumor effect of the combination therapy of bevacizumab and AdSGE-REIC on mice harboring intracerebral U87 $\triangle$ EGFR glioma cells (Fig. 4A). We compared mice bearing U87 $\triangle$ EGFR glioma cells treated with saline, bevacizumab at $10 \mathrm{mg} / \mathrm{kg}$, Ad-SGEREIC at $3.6 \times 10^{7} \mathrm{pfu}$, and bevacizumab at $10 \mathrm{mg} / \mathrm{kg}$, and Ad-SGE-REIC at $3.6 \times 10^{7} \mathrm{pfu}$ and bevacizumab at $10 \mathrm{mg} / \mathrm{kg}$. Control mice treated with PBS had a median survival of 14 days after tumor cell implantation, and mice treated with Ad-SGE-REIC similarly had a median survival of 14 days after tumor cell implantation (Fig. 4B). Mice treated with bevacizumab had a median survival of 19 days after tumor cell implantation. However, mice treated with the bevacizumab and Ad-SGE-REIC combination had a median survival of 29 days, which was significantly longer than mice treated with PBS, Ad-SGE-REIC alone, or bevacizumab alone (log-rank test: $\mathrm{p}=0.004, \mathrm{p}=0.005$, and $\mathrm{p}=0.003$, respectively).

We next evaluated the potential antitumor effect with single cell invasive model (supplementary data). We compared mice bearing MGG23 glioma cells treated with PBS, bevacizumab at $10 \mathrm{mg} / \mathrm{kg}$, Ad-SGE-REIC at $3.6 \times 10^{7} \mathrm{pfu}$, and bevacizumab at $10 \mathrm{mg} / \mathrm{kg}$, and Ad-SGE-REIC at $3.6 \times 10^{7} \mathrm{pfu}$ and bevacizumab at $10 \mathrm{mg} / \mathrm{kg}$. Control mice treated with PBS had a median survival of 70 days after tumor cell implantation, and mice treated with bevacizumab similarly had a median survival of 75 days after tumor cell implantation (Fig. 4B). Mice treated with Ad-SGE-REIC prolonged a median survival of 88 days after tumor cell implantation. However, mice treated with the bevacizumab and Ad-SGE-REIC combination had a median survival of 89 days, which was not significantly longer than mice treated with Ad-SGE-REIC alone.

\section{Effect of combination Ad-SGE-REIC with bevacizumab on angiogenesis in vivo}

Athymic mice harboring U87 $\triangle$ EGFR cell-derived brain tumors were sacrificed at 18 days after 
tumor implantation and immunohistochemical staining using anti-human CD31 was performed (Fig. 5A). Treatment with bevacizumab significantly decreased vessel density compared with controls $(\mathrm{p}<0.005)$ (Fig. 5B). In the group treated with Ad-SGE-REIC, vessel density was significantly increased compared with controls. However, treatment of bevacizumab combined with Ad-SGE-REIC significantly decreased the vessel density compared with levels in Ad-SGEREIC-treated mice $(\mathrm{p}<0.005)$.

\section{Effect of Ad-SGE-REIC on bevacizumab-induced invasion in vivo}

In another experiment, immunodeficient mice harboring U87 $\triangle$ EGFR glioma cells were sacrificed at 18 days after tumor implantation, and immunohistochemical staining with antihuman leukocyte antigen was performed. U87 $\triangle E$ GFR cells treated with bevacizumab alone showed greater invasion to the ipsilateral cerebral cortex adjacent to the injection site compared with saline controls or the combined bevacizumab and Ad-SGE-REIC treated group (Figure 5C). Invasion activity was assessed by the number of tumor cells in the ipsilateral cerebral cortex. We observed a significant increase of glioma cells invading into the cerebral cortex in the bevacizumab-treated U87 $\triangle$ EGFR cell group compared with saline controls $(\mathrm{p}<0.05)$. However, combination therapy with bevacizumab and Ad-SGE-REIC significantly decreased the depth of glioma invasion induced by bevacizumab (ipsilateral cortex: $p<0.05$, Figure 5D). These results demonstrated that Ad-SGE-REIC reduced bevacizumab-induced invasion of glioma cells.

\section{Microarray analysis of the effect of combination treatment on the U87AEGFR orthotopic mouse model}

To more closely examine the tumor microenvironment response to the combination therapy, we analyzed the changes in gene expression in tumor tissues from the U87 $\Delta$ EGFR orthotopic mouse model treated with Ad-SGE-REIC and bevacizumab combination 
therapy compared with tissues from mice treated with Ad-SGE-REIC monotherapy. We identified 937 upregulated genes and 2565 downregulated genes in Ad-SGE-REIC-treated U87 $\triangle$ EGFR glioma brain tissue compared with control glioma tissue. We also identified 934 upregulated genes and 397 downregulated genes in the combination treatment group compared with the Ad-SGE-REIC-treated U87 $\triangle$ EGFR glioma tissue.

We then characterized the functional significance of these dysregulated genes using pathway analysis. For the upregulated genes in Ad-SGE-REIC-treated U87 $\Delta$ EGFR glioma brain tissue compared with controls, 14 significantly enriched pathways were identified, including ‘TNF-alpha NF-kB Signaling Pathway,' 'Wnt Signaling Pathway NetPathand,' and 'IL-2 Signaling Pathway' (Table 1A). For the downregulated genes in Ad-SGE-REIC-treated U87 $\triangle$ EGFR glioma brain tissue compared with controls, 24 significantly enriched pathways were identified, such as 'Notch Signaling Pathway,' 'TNF-alpha NF-kB Signaling Pathway,' and 'Mitochondrial Gene Expression' (Table 1B). For the upregulated genes in the combination treated tissue compared with Ad-SGE-REIC-treated U87 $\triangle$ EGFR glioma tissue, 12 significantly enriched pathways were identified, such as 'TNF-alpha NF-kB Signaling Pathway' and 'DeltaNotch Signaling Pathway' (Table 2A). For the downregulated genes in the combination treated tissue compared with Ad-SGE-REIC-treated U87 $\triangle$ EGFR glioma tissue, 7 significantly enriched pathways were identified, including 'Robo4 and VEGF Signaling Pathways Crosstalk' and 'TNF-alpha NF-kB Signaling Pathway' (Table 2B).

\section{DISCUSSION}

Our results indicate that combination therapy of bevacizumab with Ad-SGE-REIC had additional therapeutic effects on glioma cells compared with monotherapy using bevacizumab or Ad-SGE-REIC. After treatment with Ad-SGE-REIC and bevacizumab, the number of surviving malignant glioma cells was significantly decreased in a time-dependent manner. Western blot analyses also showed increased expression of several ER stress markers in cells treated with 
both bevacizumab and Ad-SGE-REIC. Additionally, $\beta$-catenin protein levels were potently decreased by combination therapy. In malignant glioma mouse models, overall survival was extended in the combination therapy group. Our results showed that invasive activity increased by bevacizumab counteracted the effectiveness of bevacizumab. However, our experiments using two different mouse glioma models indicated that Ad-SGE-REIC inhibited glioma cell invasion induced by bevacizumab, resulting in a synergistic effect.

\section{Ad-SGE-REIC}

The Ad-SGE-REIC adenovirus vector was developed to increase REIC/Dkk-3 expression and showed enhanced therapeutic effects. We previously showed that Ad-SGE-REIC exhibited timedependent and significant effects on reducing the number of viable malignant glioma cells in cytotoxicity assays ${ }^{18}$. Xenograft and syngeneic mouse intracranial glioma models treated with Ad-SGE-REIC had significantly longer survival than those treated with the control Ad-LacZ vector or Ad-CAG-REIC ${ }^{18}$. Moreover, MGG 23 human primary culture xenograft mouse intracranial glioma models treated with Ad-SGE-REIC had significantly longer survival than controls.

\section{Combination effect of Ad-SGE-REIC with bevacizumab}

In our previous study, we observed a decreased number of vessels in the tumor xenograft model treated with bevacizumab ${ }^{11}$, and we demonstrated prolonged survival of mouse treated with bevacizumab. The VEGF autocrine signaling loop is suppressed, the Akt and Erk pathways are activated, and tumor growth and invasion are stimulated by anti-VEGF therapy ${ }^{19}$. Molecules within the extracellular matrix microenvironment such as proteoglycans and collagens may influence tumor invasion during anti-VEGF therapy ${ }^{20}$. Our results showed that REIC could inhibit glioma invasion induced by bevacizumab in vitro and in vivo.

ER stress markers and $\beta$-catenin in the nucleus were downregulated in response to the 
combination treatment. These results correlated with anti-invasive effects, which were associated with IRE1 $\alpha$ endoribonuclease activity ${ }^{21,22}$. In microarray data, the significantly enriched pathways including 'TNF-alpha NF-kB Signaling Pathway' were identified in the combination treatment sample compared with Ad-SGE-REIC alone sample. 'TNF-alpha NF-kB Signaling Pathway' is upstream of ER stress ${ }^{23}$. We need investigate more information for this upstream pathway.

The Wnt/ $\beta$-catenin signaling plays an essential role in cellular proliferation, migration, invasion, and angiogenesis, therefore contributing to glioma progression ${ }^{24}$. Notch1 promotes glioma cell migration and invasion by stimulating $\beta$-catenin ${ }^{25}$. In microarray data, the significantly enriched pathways including the 'Notch Signaling Pathway' and 'Delta-Notch Signaling Pathway' were identified in the combination treatment sample compared with AdSGE-REIC alone sample. The Notch signaling pathway is an evolutionarily conserved intercellular signaling mechanism essential for proper embryonic development in all metazoan organisms in the Animal kingdom (https://www.wikipathways.org/index.php/Pathway:WP29).

\section{Anti-angiogenic effect of bevacizumab on angiogenesis after REIC treatment}

REIC was reported to be induced angiogenesis. Untergasser reported that Dkk-3 is expressed in tumor endothelial cells and supports capillary formation ${ }^{26}$. Dkk-3 was also reported to upregulate VEGF in cultured human endothelial cells by activating the activin receptor-like kinase 1 pathway ${ }^{27}$. Our in vitro and in vivo angiogenesis evaluations revealed significant differences in angiogenesis induced with REIC between control and Ad-SGE-REIC. It might have the induction of angiogenesis in brain tumor with REIC protein. However, decreasing of angiogenesis with bevacizumab absolutely supported for Ad-SGE-REIC treatment.

\section{Future directions}

Ad-REIC is being evaluated in clinical studies. The first in-human, phase I/IIa study of in situ 
Ad-REIC gene therapy for prostate cancer and a phase I/II clinical trial of Ad-SGE-REIC for malignant mesothelioma was performed in Japan ${ }^{28,29}$. Recently, the safety and efficacy of AdSGE-REIC to liver tumors in patients are evaluated in a Phase I/Ib study ${ }^{30}$. We have started a phase I/IIa clinical trial of Ad-SGE-REIC for the treatment of recurrent malignant glioma, reviewed by the institutional review board (IRB) in March 2019. This is an open-label, singlearmed, phase I/IIa study ${ }^{31}$.

We previous showed that the integrin antagonist cilengitide improved the effect of Ad-REIC gene therapy for malignant glioma ${ }^{32}$. In addition, Oka et al. reported that immune cells infiltrated tumors treated with Ad-SGE-REIC ${ }^{18}$. We plan to evaluate other combination therapies of Ad-SGE-REIC and molecular targeted therapy, as well as immunotherapy.

\section{CONCLUSION}

We demonstrated the anti-glioma effect of Ad-SGE-REIC. Moreover, our results suggest that combination therapy of Ad-SGE-REIC and bevacizumab exhibits anti-glioma effects by upregulating the ER stress pathway, downregulating the Wnt signaling pathway, and suppressing angiogenesis and invasion of tumor cells. Combined Ad-SGE-REIC and bevacizumab may indicate a promising strategy for the treatment of malignant glioma. A phase I/IIa clinical trial of Ad-SGE-REIC for the treatment of recurrent malignant glioma is in progress.

\section{MATERIALS AND METHODS}

\section{Cell lines, drugs, and adenovirus vector}

The human glioma cell lines U87 $\mathrm{EGFR,} \mathrm{U87MG,} \mathrm{U251MG,} \mathrm{A172,} \mathrm{and} \mathrm{LNZ308} \mathrm{were}$ prepared and/or maintained as described previously ${ }^{33}$. The human glioblastoma-derived cell lines MGG8, MGG18, and MGG23 were provided by Dr. Hiroaki Wakimoto at Massachusetts General Hospital and cultured as previously described ${ }^{34,35}$. The human GBM cell lines were U87 $\triangle$ EGFR and U251MG provided by Dr. Balveen Kaur (University of Texas Health Science 
Center, Houston, TX). U87MG cells were purchased from the American Type Culture Collection. A172 and LNZ308 cells were provided by Dr. E.Antonio Chiocca (Brigham and Women's Hospital, Boston, MA).

Human umbilical vein endothelial cells (HUVECs) were purchased from Lonza (Bail, Switzerland). Mycoplasma was negative in all cells. Bevacizumab was purchased from Genentech (San Francisco, CA, USA)/Roche (Basel, Switzerland)/Chugai Pharmaceutical Co (Tokyo, Japan). Ad-SGE-REIC (adenovirus vector, $1.02 \times 10^{12}$ viral particles) was provided as described previously ${ }^{18,36}$.

\section{Cytotoxicity assay}

Cells were cultured in flat-bottomed six-well dishes at a concentration of $4.0 \times 10^{5}$ cells $/$ well. The cells were treated with PBS (control), Ad-SGE-REIC at an MOI of 30 (SGE), $1 \mathrm{mg} / \mathrm{mL}$ bevacizumab (bev), or both Ad-SGE-REIC and bevacizumab (SGE+bev). At 0, 24, 48, 72, and $96 \mathrm{~h}$ later, cell viability was examined. The number of living cells attached to the bottom of each culture well and floating in medium was determined by trypan blue staining and counted using the LUNA-II automated cell counter (Logos Biosystems, Anyang, South Korea).

\section{Sphere-forming assay}

MGG8 and MGG23 cells were dissociated by trypsin and plated in Neurobasal medium (Invitrogen) supplemented with $3 \mathrm{mmol} /$ L 1-Glutamine (Mediatech), 1× B27 supplement without vitamin A (Life Technologies), 0.5× N2 supplement (Life Technologies), $20 \mathrm{ng} / \mathrm{mL}$ recombinant human EGF (R \& D systems), 20 ng/mL recombinant human FGF2 (Peprotech), and 0.5× penicillin G/streptomycin sulfate/amphotericin B complex (Mediatech). A total of $2 \times 10^{3}$ cells/well were plated in 24-well ultra low attachment plates (Corning; Lowell, MA, USA) ${ }^{37}$. The cells were infected with Ad-SGE-REIC at an MOI of 30 or treated with $1 \mathrm{mg} / \mathrm{mL}$ bevacizumab. Spheres that formed after 10 days were counted. 


\section{Western blot analysis}

Total cell protein was extracted from cells in ice-cold lysis buffer $(20 \mathrm{mM}$ Tris $\mathrm{pH} 7.5,150 \mathrm{mM}$ NaCl, 1 mM EDTA, 1 mM EGTA, 1.0\% Triton X-100, one tablet per 10cc buffer of PhosSTOP (Roche Applied Science, Mannheim, Germany), and protease inhibitor cocktail) and quantified using the Bradford method ${ }^{38}$. Equal amounts of protein $(20 \mu \mathrm{g})$ were separated by SDS-PAGE. Then, we performed Western blotting as described previously ${ }^{13,18,36}$. The primary antibodies included mouse anti-human REIC/DKK-3 (Momotarou-gen Inc., Okayama, Japan), rabbit antipIRE1 $\alpha$ (Novus Biologicals, Littleton, CO, USA), rabbit anti-human BiP, rabbit anti-human $\beta$ catenin, rabbit anti-human caspase-9 (Cell Signaling Technology, Danvers, MA, USA), and mouse anti-human $\beta$-actin antibody (Sigma, St Louis, MO, USA); all primary antibodies were diluted 1:2000 in Can Get Signal ${ }^{\circledR}$ (TOYOBO Co., LTD. Life Science Department, Osaka, Japan). The secondary antibody horseradish peroxidase-conjugated anti-mouse or anti-rabbit IgG (Cell Signaling Technology) was diluted 1:5000 (REIC/Dkk-3, pIRE1 $\alpha$, BiP,caspase-9, $\beta$ catenin, and $\beta$-actin,) in $1 \%$ skim milk ${ }^{18}$.

\section{Tube formation assay}

EGM $^{\mathrm{TM}}$-2 Endothelial Growth Medium-2 BulletKit ${ }^{\mathrm{TM}}$, HBSS, Trypsin/EDTA, and Trypsin neutralizing solution (Lonza, USA) were used according to the manufacturer's instructions. Matrigel ${ }^{\circledR}\left(\right.$ CORNING, USA) was thawed overnight in the refrigerator at $4{ }^{\circ} \mathrm{C}$; 96 -well culture plate and pipetting tips were pre-cooled with Matrigel in the refrigerator overnight and kept on ice during the coating process. Matrigel was added to 96 -well culture plates ( $50 \mu \mathrm{L}$ per well), and the plate was incubated at $37^{\circ} \mathrm{C}$ for 30 min. HUVECs were plated in the plates $\left(2.0 \times 10^{4}\right)$ with conditioned medium obtained by cultivating U251 at cytotoxicity assay. After $24 \mathrm{~h}$, the cells were viewed under a microscope (BZ-8000; Keyence, Osaka, Japan). The total tube length in each well was calculated under high magnification (x20), and the average length of four wells 
in each treatment group was taken as the tube formation per view field.

\section{Transwell migration assay}

In vitro migration assays were performed using a 24 -well plate and ThinCert ( $8 \mu \mathrm{m}$-pore, 24 well format, Greiner Bio-one; Kremsmunster, Austria) according to the manufacturer's instructions. We prepared U87 $\mathrm{EGFR}$ cells as described previously ${ }^{11}$, and cells were treated with PBS, bevacizumab, and/or Ad-SGE-REIC as in the cytotoxicity assay. After the treatments, the CM and cells of each treatment group were collected. The upper chamber was filled with 2.0 $\times 10^{5}$ U87 $\triangle$ EGFR cells in $200 \mu \mathrm{L} \mathrm{CM}$; the lower chamber was filled with DMEM with $10 \%$ FBS as a chemoattractant with or without $1 \mathrm{mg} / \mathrm{mL}$ bevacizumab. After a 24-h incubation, noninvading cells were scraped from the top compartment. The insert filters were stained with 5\% Giemsa solution, and the number of invading cells was counted on the lower surface of the filter 12,39

\section{Ethics and animal use statement}

This study was conducted in strict accordance to the recommendations in the Guide for the Care and Use of Laboratory Animals in Japan. All procedures and animal protocols were in accordance with arrive guidelines and approved by the Committee on the Ethics of Animal Experimentation at Okayama University (Permit No. OKU-2016554).

\section{Brain xenografts}

Athymic mice (BALB/c-nu/nu) were obtained from CLEA Japan, Inc. (Tokyo, Japan). We prepared $2.0 \times 10^{5} \mathrm{U} 87 \Delta \mathrm{EGFR}$ or, MGG23 cells/ $\mu \mathrm{L}$ as described previously ${ }^{11}$. They were anesthetized with an intraperitoneal (ip) injection of ketamine $(2.7-3.0 \mathrm{mg} / 100 \mathrm{~g})$ and xylazine $(0.36-4.0 \mathrm{mg} / 100 \mathrm{~g})$. Cells $(2 \mu \mathrm{L})$ were injected into the right frontal lobe of mice $(3 \mathrm{~mm}$ lateral and $1 \mathrm{~mm}$ anterior to the bregma at a depth of $3 \mathrm{~mm}$ ), as described previously. PBS or 
bevacizumab $(10 \mathrm{mg} / \mathrm{kg})$ was intraperitoneally administered two times per week, starting on day 5 after tumor cell implantation. At 7 days after tumor inoculation, all mice bearing brain tumors were reanesthetized and stereotactically injected with Ad-SGE-REIC or PBS at the tumor inoculation site using the same coordinates. We assessed the survival time of the U87 $\mathrm{EGFR}$ mouse glioma model using Kaplan-Meier survival analysis.

Animals were sacrificed at 28 days after tumor implantation, following six administrations of PBS or bevacizumab. The maximum transverse diameter of tumors was measured. Hematoxylin and eosin staining was performed as described previously ${ }^{40}$.

\section{Immunohistochemistry}

Immunohistochemistry was performed using the avidin-biotin-peroxidase complex method (Ultrasensitive; MaiXin, Fuzhou, China). CD31 mouse monoclonal antibody (1:300 dilution; Abcam, Inc., Cambridge, UK) and mouse immunoglobulin (a negative control) were used as previously described ${ }^{34}$. Hematoxylin was used for counterstaining. We evaluated the positivity of cytoplasmic immunostaining in tumor cells.

\section{Microarray analysis}

Orthotopic U87 $\triangle$ EGFR xenograft mouse models treated with control, Ad-SGE-REIC or the combination of bevacizumab and Ad-SGE-REIC were killed at 18 days after tumor implantation $(\mathrm{n}=3$ per treatment). Approximately $40 \mathrm{mg}$ of brain tumor samples were excised cleanly from each mouse, and RNA was extracted using TRIzol (Life Technologies, Carlsbad, CA, USA) and an RNeasy Mini Kit (Qiagen, Venlo, Netherlands). Samples were analyzed using the SurePrint G3 Mouse GE Microarray 8x60K Ver2.0 (Agilent, Tokyo, Japan). We entrusted the microarray analyses to DNA Chip Research Inc. (Tokyo, Japan). Amplification and biotin labeling of fragmented cDNA was performed using NuGEN Ovation Pico WTA System V2 (NuGEN Technologies Inc.). Labeled probes were hybridized to the Agilent SurePrint G3 Mouse Gene 
Expression 8x60K and scanned. Expression data were extracted from image files produced on an Agilent microarray scanner (Agilent). The scanned images were analyzed with Agilent Feature Extraction 12.1.1.1 (Agilent). Genechip analysis was performed using GeneSpring GX 14.9.1 software (Agilent). The median shift normalization to 75 percentile and baseline transformation using the median of all samples was applied ${ }^{41}$.

A gene was defined as upregulated when Ad-SGE-REIC monotherapy/control or the combination therapy/Ad-SGE-REIC monotherapy average intensity ratio was $>4.0$ and downregulated when Ad-SGE-REIC monotherapy/control or the combination therapy/Ad-SGEREIC monotherapy ratio was $<0.25$. We performed pathway analysis on the genes with upregulated and downregulated expression using Microarray Data Analysis ToolVer3.2 (Filgen, Inc.). The data were extracted using the following criteria: $\mathrm{Z}$ score $>0$ and $\mathrm{p}$ value $<0.05^{11,42}$.

\section{Statistical analysis}

The Student's t-test, Mann-Whitney U test, and ANOVA were used to test for statistical significance. Data are presented as the mean \pm standard deviation and standard error. Differences were considered to denote statistical significance when $p<0.05$. All statistical analyses were performed using SPSS statistical software, version 20 (SPSS, Inc., Chicago, IL, USA). 


\section{References}

1 Stupp, R. et al. Radiotherapy plus concomitant and adjuvant temozolomide for glioblastoma. $N$ Engl J Med 352, 987-996, doi:10.1056/NEJMoa043330 (2005).

2 Mooney, J. et al. Current approaches and challenges in the molecular therapeutic targeting of glioblastoma. World neurosurgery (2019).

3 Touat, M., Idbaih, A., Sanson, M. \& Ligon, K. L. Glioblastoma targeted therapy: updated approaches from recent biological insights. Annals of oncology : official journal of the European Society for Medical Oncology 28, 1457-1472, doi:10.1093/annonc/mdx106 (2017).

4 Kurozumi, K., Ichikawa, T., Onishi, M., Fujii, K. \& Date, I. Cilengitide treatment for malignant glioma: current status and future direction. Neurologia medico-chirurgica 52, 539-547 (2012).

5 Bokstein, F., Shpigel, S. \& Blumenthal, D. T. Treatment with bevacizumab and irinotecan for recurrent high-grade glial tumors. Cancer 112, 2267-2273, doi:10.1002/cncr.23401 (2008).

6 Vredenburgh, J. J. et al. Bevacizumab plus irinotecan in recurrent glioblastoma multiforme. Journal of clinical oncology : official journal of the American Society of Clinical Oncology 25, 4722-4729, doi:10.1200/JCO.2007.12.2440 (2007).

7 Dvorak, H. F. Vascular permeability factor/vascular endothelial growth factor: a critical cytokine in tumor angiogenesis and a potential target for diagnosis and therapy. Journal of clinical oncology : official journal of the American Society of Clinical Oncology 20, 4368-4380 (2002).

8 Chinot, O. L. et al. Bevacizumab plus radiotherapy-temozolomide for newly diagnosed glioblastoma. N Engl J Med 370, 709-722, doi:10.1056/NEJMoa1308345 (2014).

9 Gilbert, M. R. et al. A randomized trial of bevacizumab for newly diagnosed glioblastoma. N Engl J Med 370, 699-708, doi:10.1056/NEJMoa1308573 (2014).

10 Piao, Y. et al. Glioblastoma resistance to anti-VEGF therapy is associated with myeloid cell infiltration, stem cell accumulation, and a mesenchymal phenotype. Neuro Oncol 14, 1379-1392, doi:10.1093/neuonc/nos158 (2012).

11 Ishida, J. et al. Integrin inhibitor suppresses bevacizumab-induced glioma invasion. Transl Oncol 7, 292-302 e291, doi:10.1016/j.tranon.2014.02.016 (2014).

12 Shimizu, T. et al. delta-Catenin Promotes Bevacizumab-Induced Glioma Invasion. Mol Cancer Ther 18, 812-822, doi:10.1158/1535-7163.MCT-18-0138 (2019).

13 Otani, Y. et al. Fibroblast growth factor 13 regulates glioma cell invasion and is important for bevacizumab-induced glioma invasion. Oncogene 37, 777-786, doi:10.1038/onc.2017.373 (2018).

14 Tsuji, T., Miyazaki, M., Sakaguchi, M., Inoue, Y. \& Namba, M. A REIC gene shows downregulation in human immortalized cells and human tumor-derived cell lines. Biochem Biophys Res Commun 268, 20-24, doi:10.1006/bbrc.1999.2067 (2000).

15 Tsuji, T. et al. Antiproliferative activity of REIC/Dkk-3 and its significant down-regulation in non-small-cell lung carcinomas. Biochem Biophys Res Commun 289, 257-263, doi:10.1006/bbrc.2001.5972 (2001).

16 Abarzua, F., Sakaguchi, M. \& Takaishi, M. Adenovirus-Mediated Overexpression of REIC/Dkk-3 Selectively Induces Apoptosis in Human Prostate Cancer Cells through Activation of c-Jun-NH2-Kinase. Cancer research 65, 9617-9622, doi:10.1158/00085472.can-05-0829 (2005).

17 Kashiwakura, Y. et al. Down-regulation of inhibition of differentiation-1 via activation of activating transcription factor 3 and Smad regulates REIC/Dickkopf-3-induced apoptosis. Cancer research 68, 8333-8341, doi:10.1158/0008-5472.CAN-08-0080 (2008).

18 Oka, T. et al. A super gene expression system enhances the anti-glioma effects of 
adenovirus-mediated REIC/Dkk-3 gene therapy. Sci Rep 6, 33319, doi:10.1038/srep33319 (2016).

19 Simon, T. et al. Direct effect of bevacizumab on glioblastoma cell lines in vitro. Neuromolecular Med 16, 752-771, doi:10.1007/s12017-014-8324-8 (2014).

20 de Groot, J. F. et al. Tumor invasion after treatment of glioblastoma with bevacizumab: radiographic and pathologic correlation in humans and mice. Neuro Oncol 12, 233-242, doi:10.1093/neuonc/nop027 (2010).

21 Jabouille, A. et al. Glioblastoma invasion and cooption depend on IRE1 $\alpha$ endoribonuclease activity. Oncotarget 6, 24922 (2015).

22 Dejeans, N. et al. Autocrine control of glioma cells adhesion and migration through IRE1 $\alpha$-mediated cleavage of SPARC mRNA. J Cell Sci 125, 4278-4287 (2012).

23 Hu, P., Han, Z., Couvillon, A. D., Kaufman, R. J. \& Exton, J. H. Autocrine tumor necrosis factor alpha links endoplasmic reticulum stress to the membrane death receptor pathway through IRE1alpha-mediated NF-kappaB activation and down-regulation of TRAF2 expression. Molecular and cellular biology 26, 3071-3084, doi:10.1128/MCB.26.8.30713084.2006 (2006).

24 He, L. et al. Wnt/beta-catenin signaling cascade: A promising target for glioma therapy. $J$ Cell Physiol 234, 2217-2228, doi:10.1002/jcp.27186 (2019).

25 Zhang, X. et al. Notch1 promotes glioma cell migration and invasion by stimulating $\beta$ catenin and NF- $\kappa B$ signaling via AKT activation. Cancer science 103, 181-190 (2012).

26 Untergasser, G. et al. The Dickkopf-homolog 3 is expressed in tumor endothelial cells and supports capillary formation. International journal of cancer 122, 1539-1547 (2008).

27 Busceti, C. L. et al. Dickkopf-3 upregulates VEGF in cultured human endothelial cells by activating activin receptor-like kinase 1 (ALK1) pathway. Frontiers in pharmacology $\mathbf{8}$, 111 (2017).

28 Kumon, H. et al. Adenovirus vector carrying REIC/DKK-3 gene: neoadjuvant intraprostatic injection for high-risk localized prostate cancer undergoing radical prostatectomy. Cancer gene therapy 23, 400-409, doi:10.1038/cgt.2016.53 (2016).

29 Kumon, H. et al. Ad-REIC Gene Therapy: Promising Results in a Patient with Metastatic CRPC Following Chemotherapy. Clin Med Insights Oncol 9, 31-38, doi:10.4137/CMO.S23252 (2015).

30 Oyama, A. et al. A Phase I/Ib trial of Ad-REIC in liver cancer: study protocol. Future oncology (London, England) 15, 3547-3554, doi:10.2217/fon-2019-0115 (2019).

31 Kurozumi, K. et al. Study protocol of a Phase I/IIa clinical trial of Ad-SGE-REIC for treatment of recurrent malignant glioma. Future oncology (London, England) 16, 151-159, doi:10.2217/fon-2019-0743 (2020).

32 Shimazu, Y. et al. Integrin antagonist augments the therapeutic effect of adenovirusmediated REIC/Dkk-3 gene therapy for malignant glioma. Gene therapy 22, 146-154, doi:10.1038/gt.2014.100 (2015).

33 Kambara, H., Okano, H., Chiocca, E. A. \& Saeki, Y. An oncolytic HSV-1 mutant expressing ICP34.5 under control of a nestin promoter increases survival of animals even when symptomatic from a brain tumor. Cancer research 65, 2832-2839, doi:65/7/2832 [pii]10.1158/0008-5472.CAN-04-3227 (2005).

34 Wakimoto, H. et al. Human glioblastoma-derived cancer stem cells: establishment of invasive glioma models and treatment with oncolytic herpes simplex virus vectors. Cancer research 69, 3472-3481 (2009).

35 Wakimoto, H. et al. Maintenance of primary tumor phenotype and genotype in glioblastoma stem cells. Neuro-oncology 14, 132-144 (2011).

36 Watanabe, M. et al. A novel gene expression system strongly enhances the anticancer effects of a REIC/Dkk-3-encoding adenoviral vector. Oncol Rep 31, 1089-1095, doi:10.3892/or.2013.2958 (2014). 
37 Castellan, M. et al. Single-cell analyses reveal YAP/TAZ as regulators of stemness and cell plasticity in glioblastoma. Nature Cancer 2, 174-188, doi:10.1038/s43018-02000150-z (2021).

$38 \mathrm{Li}, \mathrm{H}$. et al. Rsf-1 overexpression in human prostate cancer, implication as a prognostic marker. Tumor Biology 35, 5771-5776 (2014).

39 Tomita, Y. et al. Oncolytic herpes virus armed with vasculostatin in combination with bevacizumab abrogate glioma invasion via the $\mathrm{CCN} 1$ and AKT signaling pathways. $\mathrm{Mol}$ Cancer Ther, doi:10.1158/1535-7163.MCT-18-0799 (2019).

40 Onishi, M. et al. Bimodal anti-glioma mechanisms of cilengitide demonstrated by novel invasive glioma models. Neuropathology : official journal of the Japanese Society of Neuropathology 33, 162-174, doi:10.1111/j.1440-1789.2012.01344.x (2013).

41 Koya, J. et al. DNMT3A R882 mutants interact with polycomb proteins to block haematopoietic stem and leukaemic cell differentiation. Nature Communications 7, 10924, doi:10.1038/ncomms10924 (2016).

42 Onishi, M. et al. Gene expression profiling of the anti-glioma effect of Cilengitide. SpringerPlus 2, 160, doi:10.1186/2193-1801-2-160 (2013). 


\section{Acknowledgments}

We would like to thank M. Arao and Y. Ukai for their technical assistance. N. Akura and N. Yamamoto, medical students at our institution, also contributed to the animal experiments. Bevacizumab was generously provided by Genentech/Roche/Chugai Pharmaceutical Co. We thank Gabrielle White Wolf, PhD, from Edanz Group (www.edanzediting.com/ac) for editing a draft of this manuscript.

This study was supported by grants-in-aid for Scientific Research from the Japanese Ministry of Education, Culture, Sports, Science, and Technology to K. Kurozumi (nos. 26462182 and 17K10865). Our department receives research funding from Momotaro-Gene Co. Ltd., but this fact will not influence the trial results. Okayama University and Momotaro-Gene Inc., a start-up biotech company from Okayama University, hold the patents for the Ad-REIC agent. They are working together on the development of the Ad-REIC agent as a cancer therapeutic medicine.

\section{Authors' Contributions}

Conception and design: Y. Hattori, K. Kurozumi

Development of methodology: Y. Hattori, K. Kurozumi, Y. Otani, A. Uneda

Acquisition of data (provided animals, acquired and managed patients, provided facilities, etc.):

\section{Y. Hattori}

Analysis and interpretation of data (e.g., statistical analysis, biostatistics, computational analysis): Y. Hattori, K. Kurozumi

Writing, review, and/or revision of the manuscript: Y. Hattori, K. Kurozumi, Y. Tomita, Y. Matsumoto, Y. Shimazu, H. Kumon, I. Date

Administrative, technical, or material support (i.e., reporting or organizing data, constructing databases): Y. Hattori, T. Oka, N. Tsuboi

Study supervision: K. Kurozumi, K. Fujii, H. Kumon, I. Date 


\section{Conflict of interest}

H Kumon is the Chief Scientific Officer of Momotaro-Gene Inc. He demonstrated the utility of the agent and also owns stocks in Momotaro-Gene Inc. The other authors have no other relevant affiliations or financial involvement with any organization or entity with a financial interest in or financial conflict with the subject matter or materials discussed in the manuscript apart from those disclosed. 


\section{Figure legends}

Figure 1. Cytotoxic effect of Ad-SGE-REIC, bevacizumab, and the combination on glioma cell lines.

U87 $\triangle E$ EFR (A) and U251MG (B) glioma cells were treated with saline as control or bevacizumab $(1 \mathrm{mg} / \mathrm{ml})$ and infected with saline or Ad-SGE-REIC (SGE; MOI of 30). Cell viability was examined every $24 \mathrm{~h}$ after infection. Data shown are the proportion of viable cells relative to control cells. Values are the mean \pm SEM from five independent experiments. Statistical significance was calculated by analysis of variance with one-way ANOVA with Tukey's post hoc test. (C), (D) The number of spheres formed from $10^{4}$ cells were counted. Data are expressed as mean \pm SD from three independent experiments. (E, F) Representative images from the sphere formation assay (C, E: MGG8 cells, D, F: MGG23 cells). ${ }^{*} \mathrm{p}<0.05,{ }^{*} \mathrm{p}<0.01$ and ${ }^{* * *} \mathrm{p}<0.001$ compared with the indicated groups.

\section{Figure 2.}

\section{Inhibition of endothelial cell tube formation.}

Human umbilical vein endothelial cells (HUVECs) were treated with medium containing vascular endothelial growth factor (VEGF)-A along with Ad-SGE-REIC and/or bevacizumab and then assayed by the KURABO Angiogenesis Kit. (A) Representative images of tube formation of HUVECs. Control: VEGF-A (10ng/ml); SGE: VEGF-A/Ad-SGE-REIC $\left(5 \times 10^{2} \mathrm{pfu}\right)$; bevacizumab: VEGF-bevacizumab $(0.1 \mathrm{mM})$; and SGE+bevacizumab: VEGF-A/ Ad-SGE-REIC/ bevacizumab. (B) Significant reduction in tube formation of HUVECs treated with Ad-SGE-REIC and bevacizumab combined compared with Ad-SGE-REIC or bevacizumab monotherapy $\left({ }^{*}<0.0090 ; * * p<0.028\right)$. (C) Representative images from the two-chamber invasion assay. Glioma cell lines were incubated with conditioned medium (CM) derived from glioma cells treated with Ad-SGE-REIC. Cells were treated with bevacizumab. (D) Invading cells were counted $24 \mathrm{~h}$ after treatment. Data shown are the number of invading cells relative to those treated with saline as a control. Data shown are the proportions of invading distance against core diameter relative to those treated with saline as a control. Values are the mean \pm SEM from five independent experiments. Statistical significance was calculated by analysis of one-way ANOVA with Tukey's post hoc test. ${ }^{*} \mathrm{p}<0.05, * * \mathrm{p}<0.01$ and $* * * \mathrm{p}<0.001$ compared with the indicated groups.

\section{Figure 3.}

ER stress in U87 $\triangle$ EGFR glioma cells after treatment with Ad-SGE-REIC. U87 $\triangle$ EGFR cells were infected with Ad-SGE-REIC at a MOI of 10. Immunoblot analysis showed that levels of REIC, BiP, and phosphorylated IRE1 $\alpha$ were increased in the U87 $\triangle E G F R(a), U 251(b)$ and MGG23(c) cells following treatment with Ad-SGE-REIC. Moreover, higher amount of protein levels showed in combination treatment. (B) U87 $\triangle$ EGFR cells were infected with Ad-SGE-REIC at an MOI of 10, or treated with bevacizumab or combination. A reduction in $\beta$-catenin expression occurred in parallel with increased expression of REIC/Dkk-3 $(n=4)$. Moreover, less amount of protein levels showed in combination treatment.

\section{Figure 4.}

Kaplan-Meier survival curves and histological analysis of mice implanted with intracranial U87 $\triangle$ EGFR glioma cells. (A) Glioma cell-bearing animals were administered saline or bevacizumab intraperitonially on the indicated days and intratumoral saline or virus on day 7. (B) Athymic nude mice bearing intracranial U87 $\triangle$ EGFR gliomas were treated with $3.6 \times 10^{7}$ pfu AdSGE-REIC, and bevacizumab was administered intraperitoneally at $10 \mu \mathrm{g} / \mathrm{g}$. Statistical significance was calculated by the log-rank test.

\section{Figure 5.}

Anti-angiogenic effect of bevacizumab. (A) Tumor vessels were identified with CD31. Untreated 
U87 $\triangle$ EGFR orthotopic tumor was observed with angiogenic growth. (B) Reduction of tumor vessels with bevacizumab therapy. Bevacizumab significantly decreased vessel density of tumors; the vessel density of the Ad-SGE-REIC-treated group was significantly increased compared with the control. In the combination treatment of Ad-SGE-REIC with bevacizumab, the vessel density was significantly decreased compared with Ad-SGE-REIC single treatment. (C) Immunohistochemical staining of the tumors with anti-human leukocyte antigen monoclonal antibody. The untreated tumor shows the expansion of the tumor with well-defined borders. (D) After treatment with bevacizumab, the tumor border became irregular with tumor invasion. ${ }^{*} \mathrm{p}<0.01$. The invasiveness was assessed by the distance between the tumor mass edge and invasive lesion. Values are the mean \pm SEM from five independent experiments. Statistical significance was calculated by analysis of one-way ANOVA with Tukey's post hoc test. 
Figure 1

A

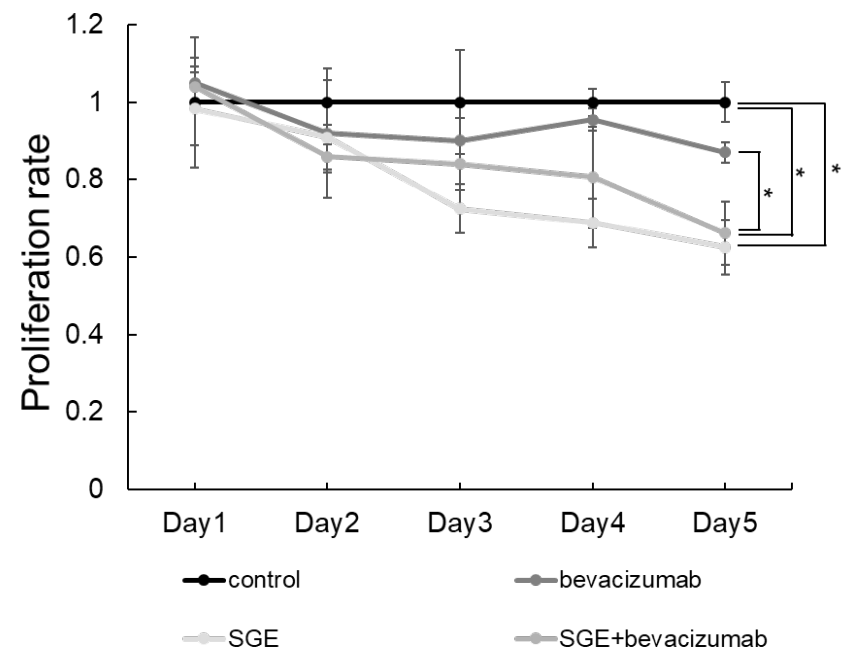

C
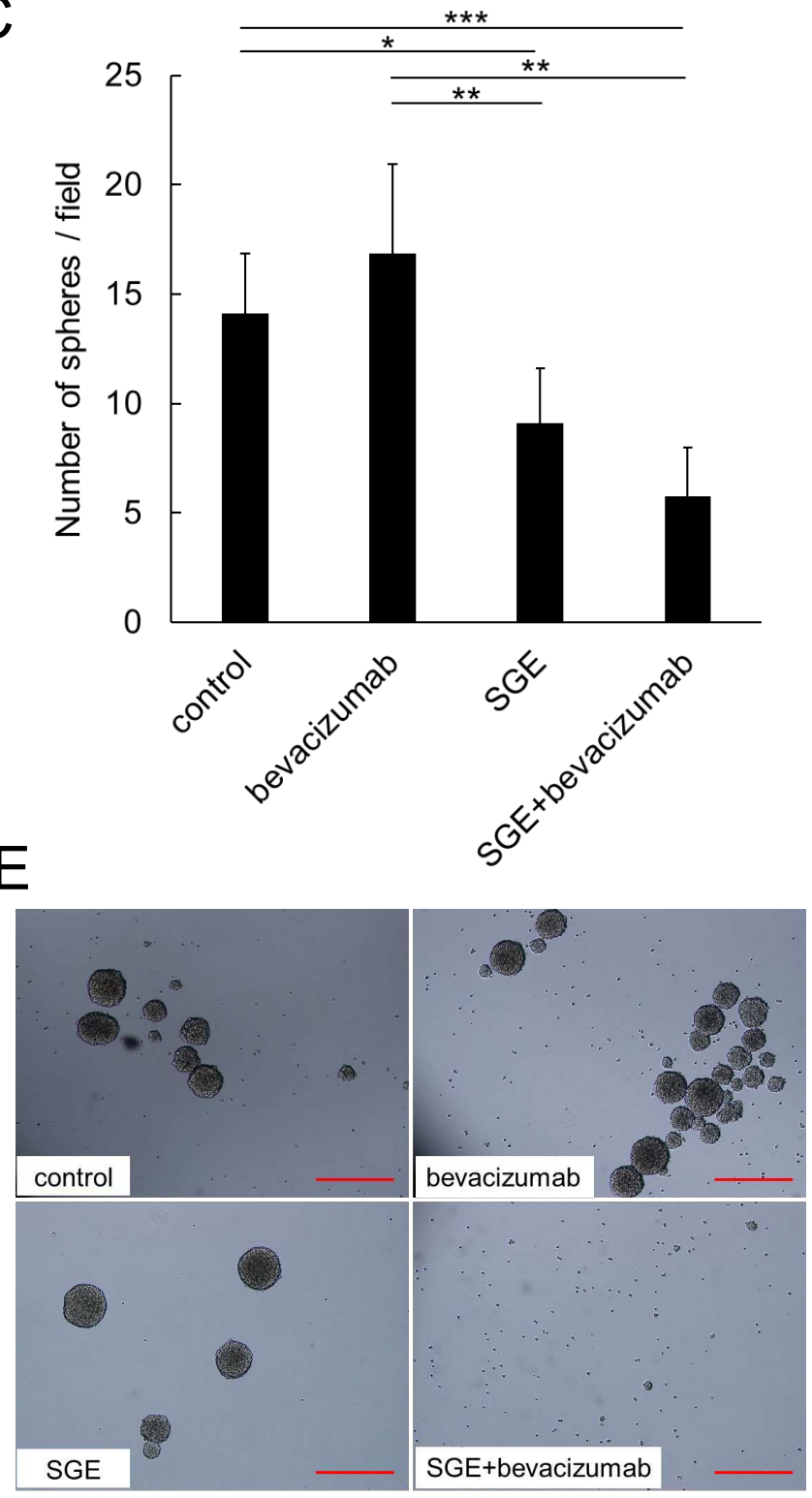

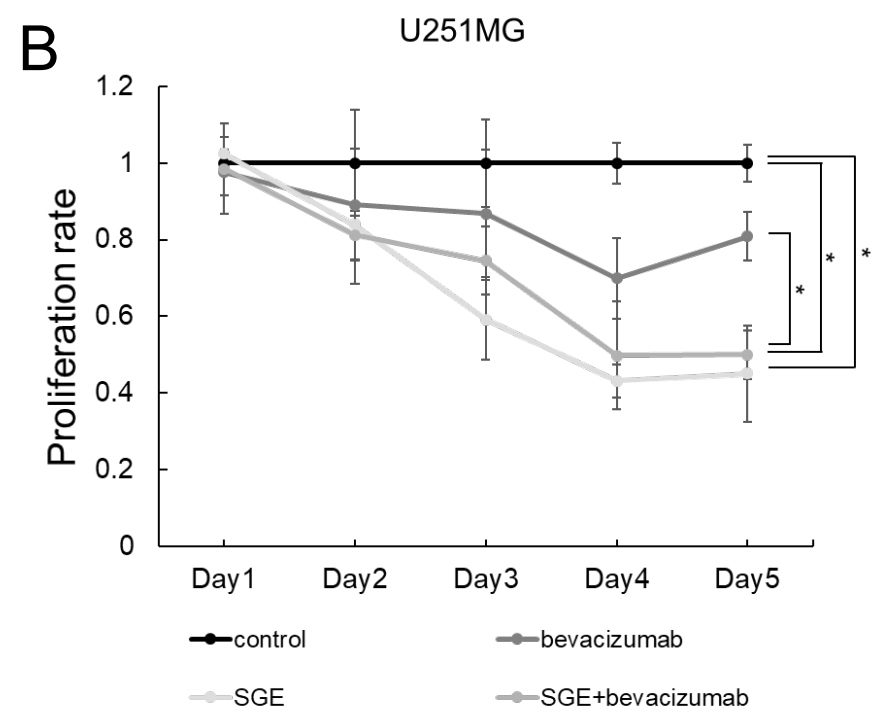

D

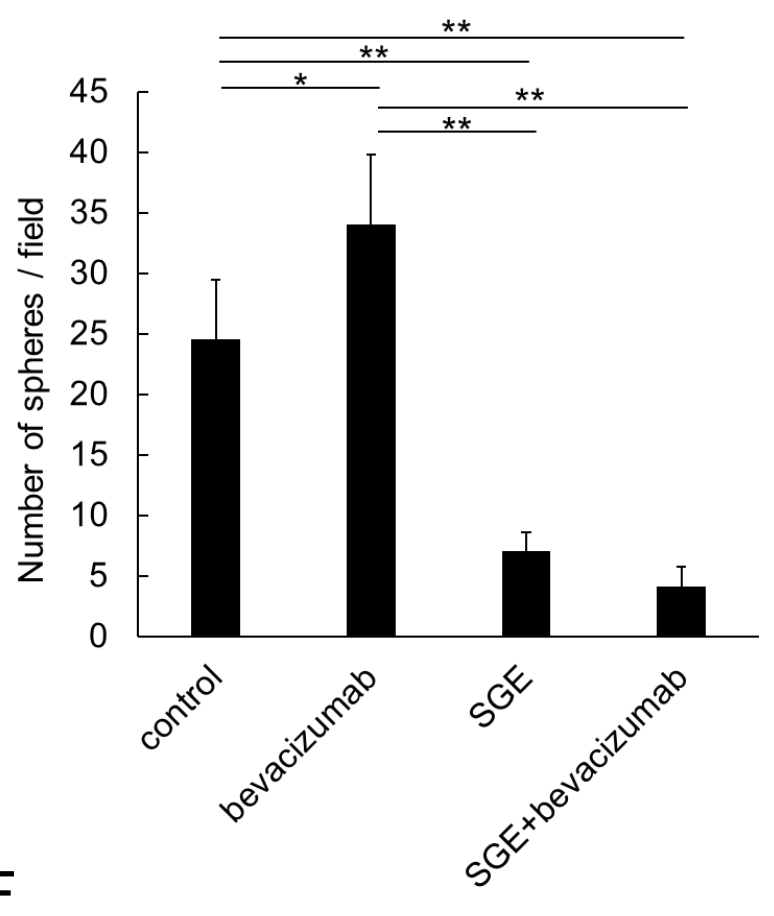




\section{Figure 2}

A

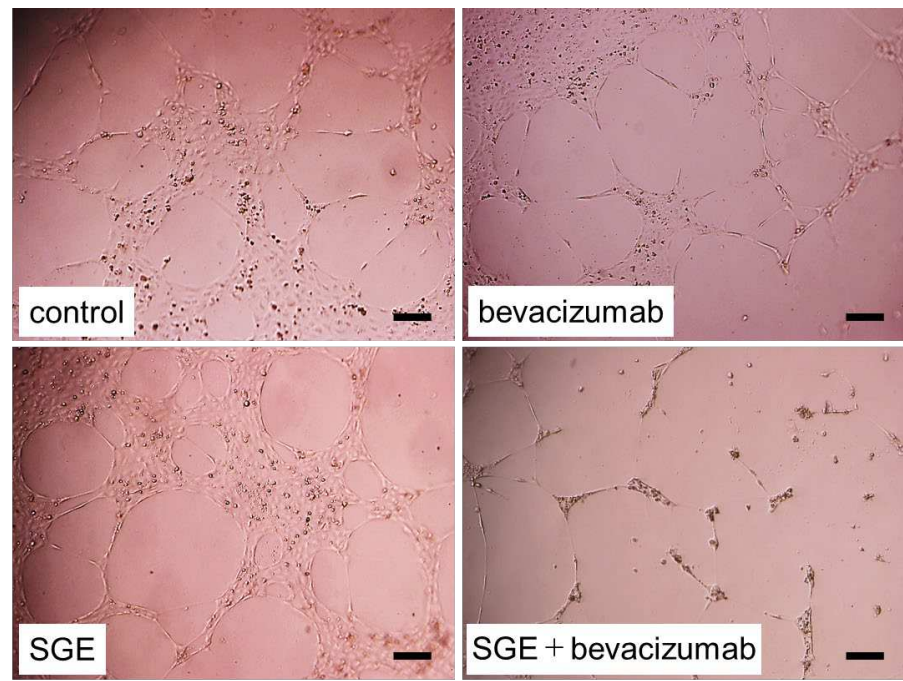

bar: $200 \mu \mathrm{m}$
B

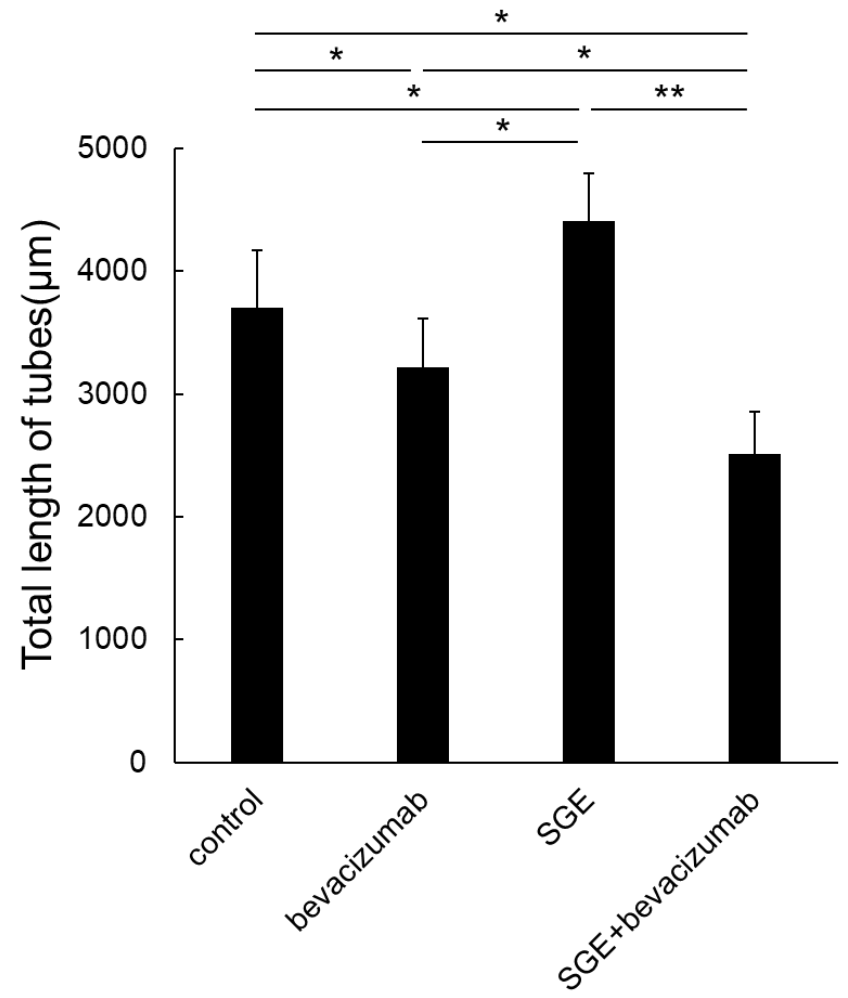

D

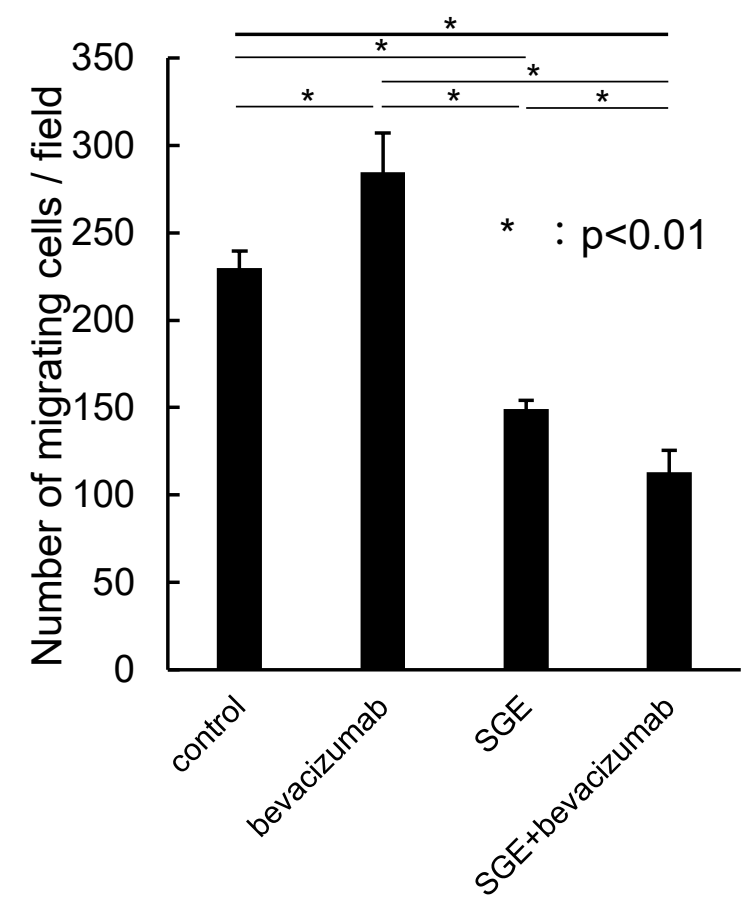

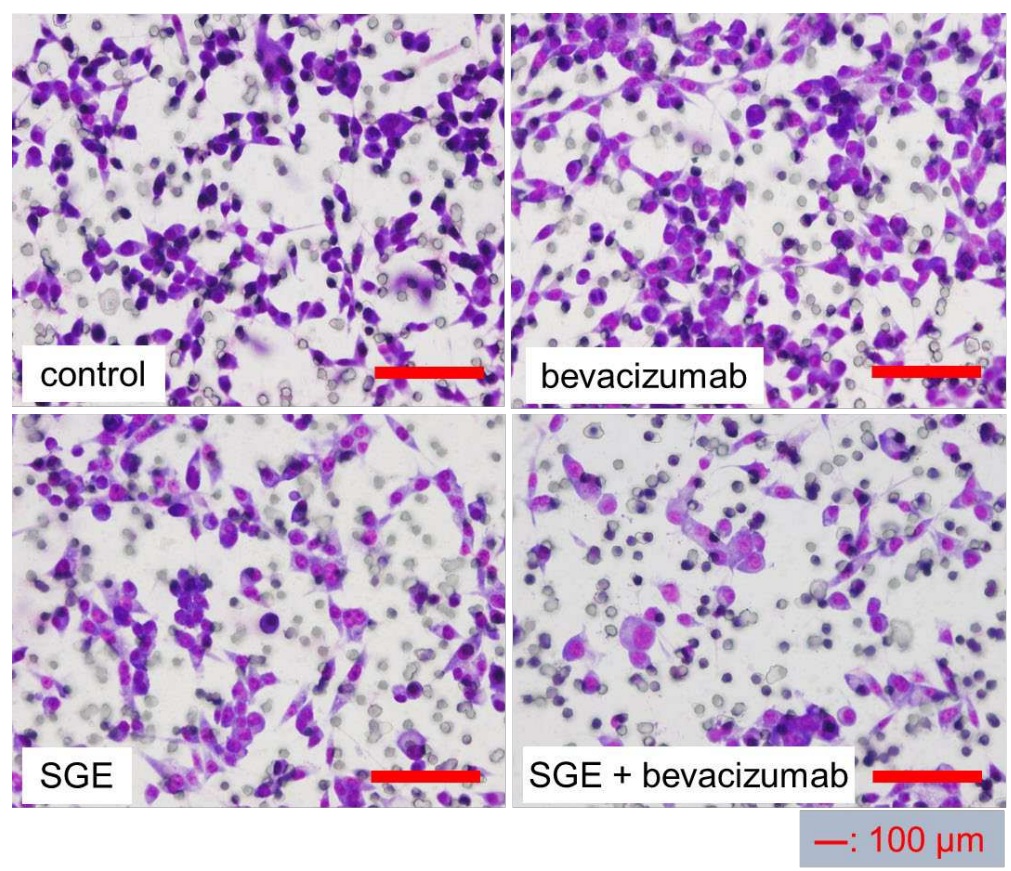


Figure 3
A
a
U87 $\triangle E G F R$
b
U251
control bev SGE SGE+bev
REIC

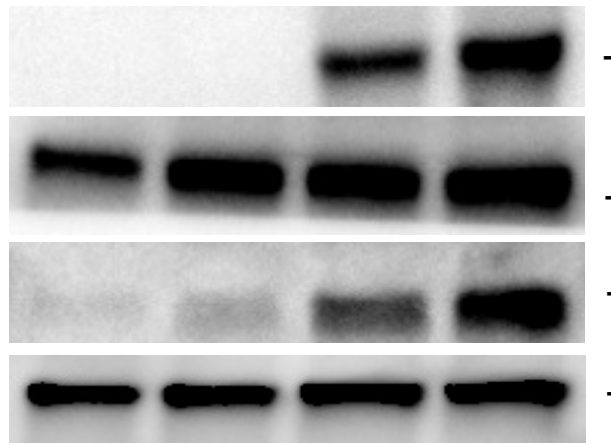
$-62 k D a$
pIRE1 $\alpha$
$\mathrm{BiP}$
$\beta$-actin
MGG23
C

$$
\text { control bev SGE SGE+bev }
$$
REIC
$-120 k D a$
pIRE1 $\alpha$
- 80kDa
$\mathrm{BiP}$
control bev SGE SGE+bev
REIC
$-62 k D a$
$-40 \mathrm{kDa}$
Actin
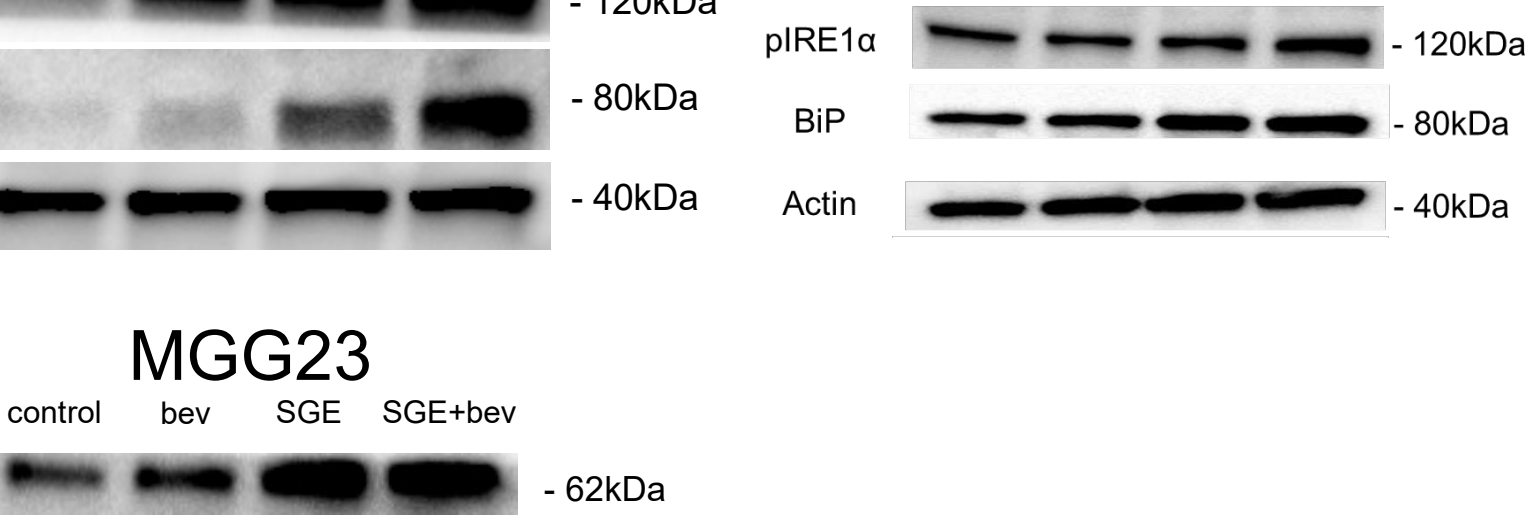
pIRE1a

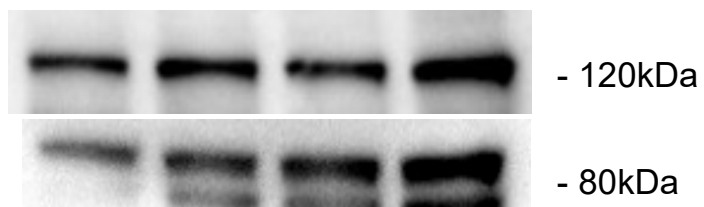
Actin
$-42 \mathrm{kDa}$
B
a $\quad$ U87 $\triangle E G F R$
b U251
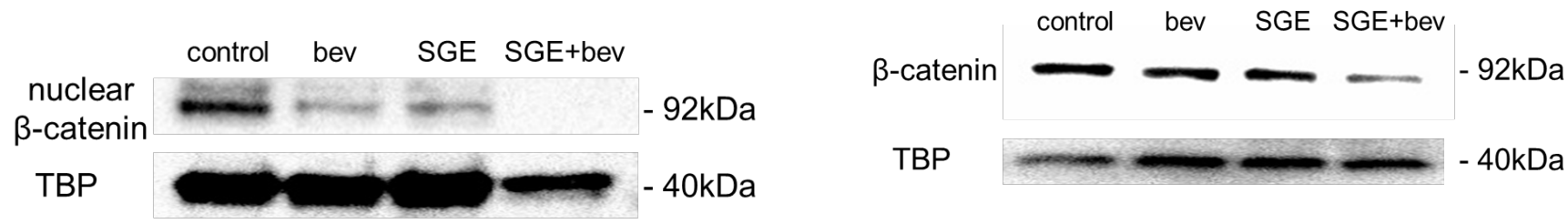
C
MGG23
control bev SGE SGE+bev
$\beta$-catenin
- 92kDa 


\section{Figure 4}

A

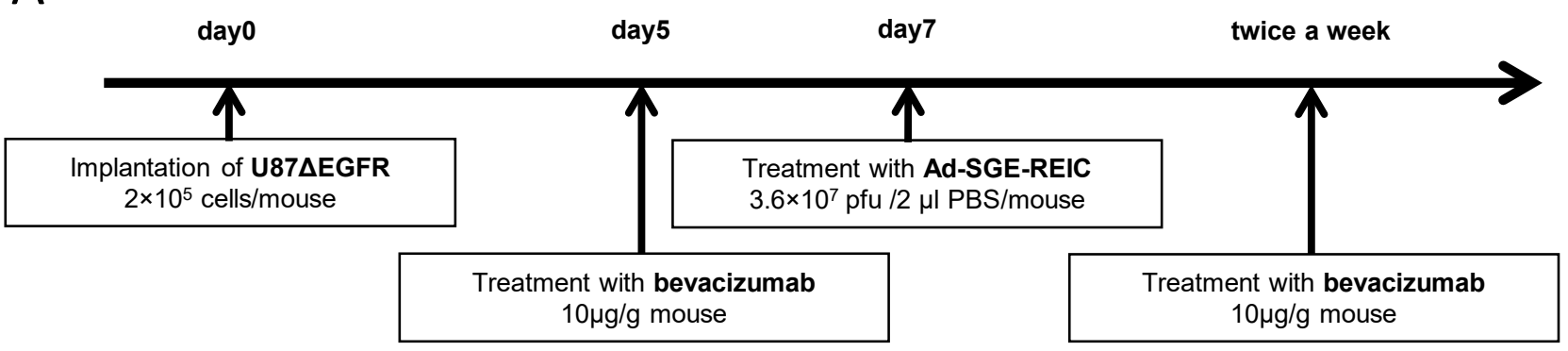

B

\section{Overall survival}

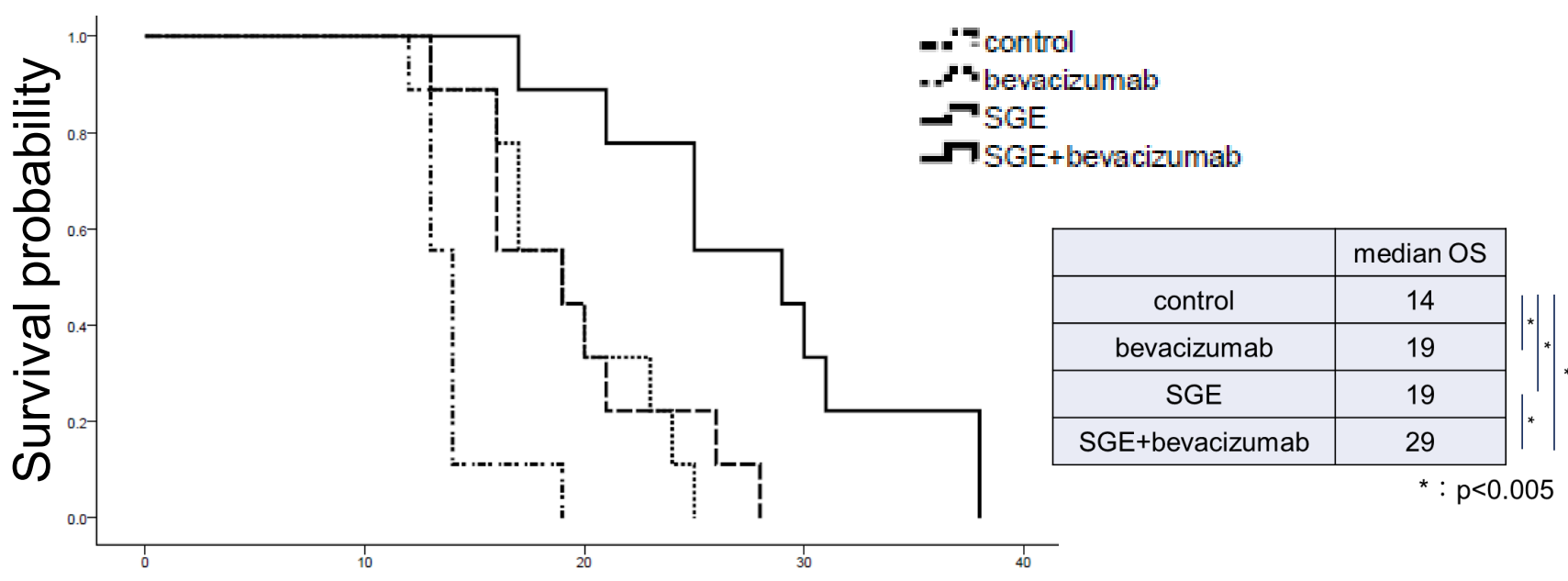


Figure 5

A
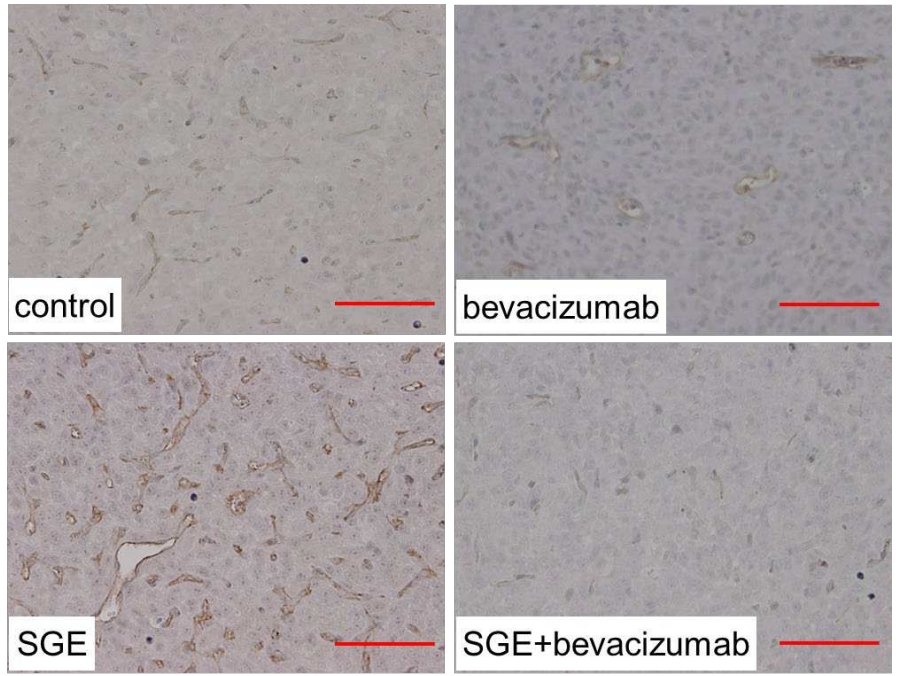

bar: $100 \mu \mathrm{m}$

C
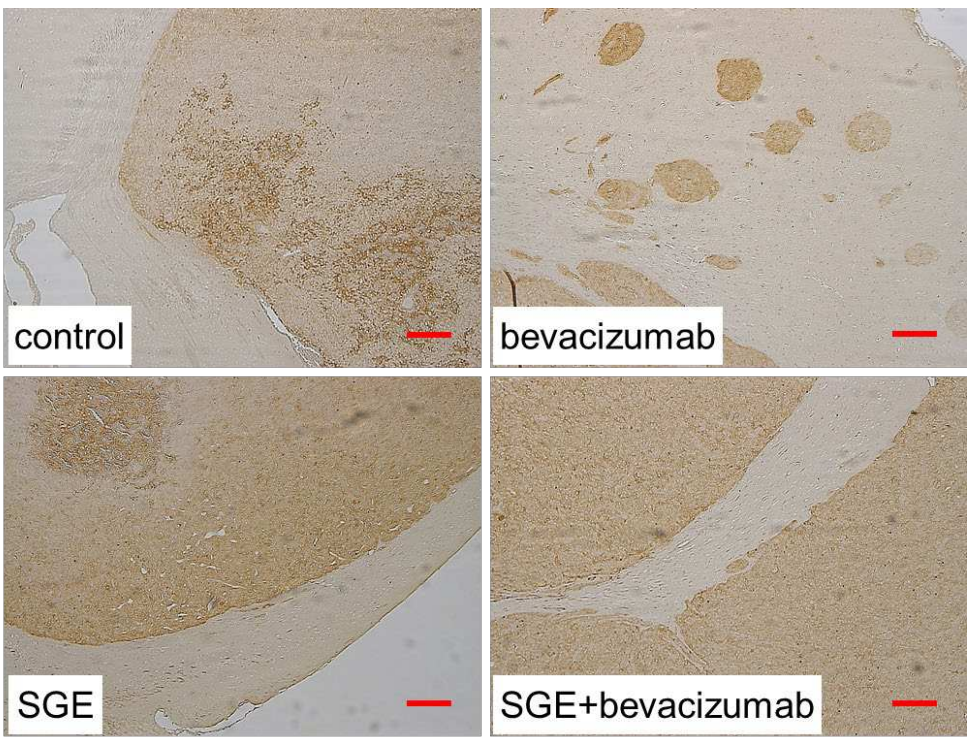

bar: $200 \mu \mathrm{m}$

\section{B}

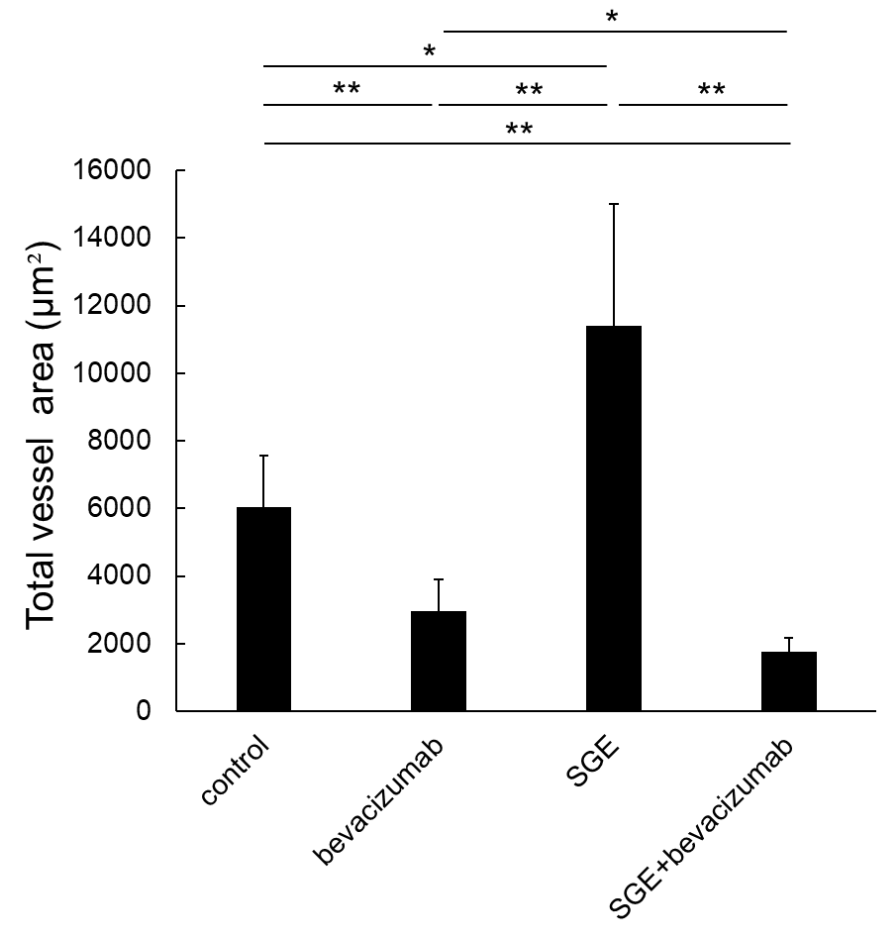

D

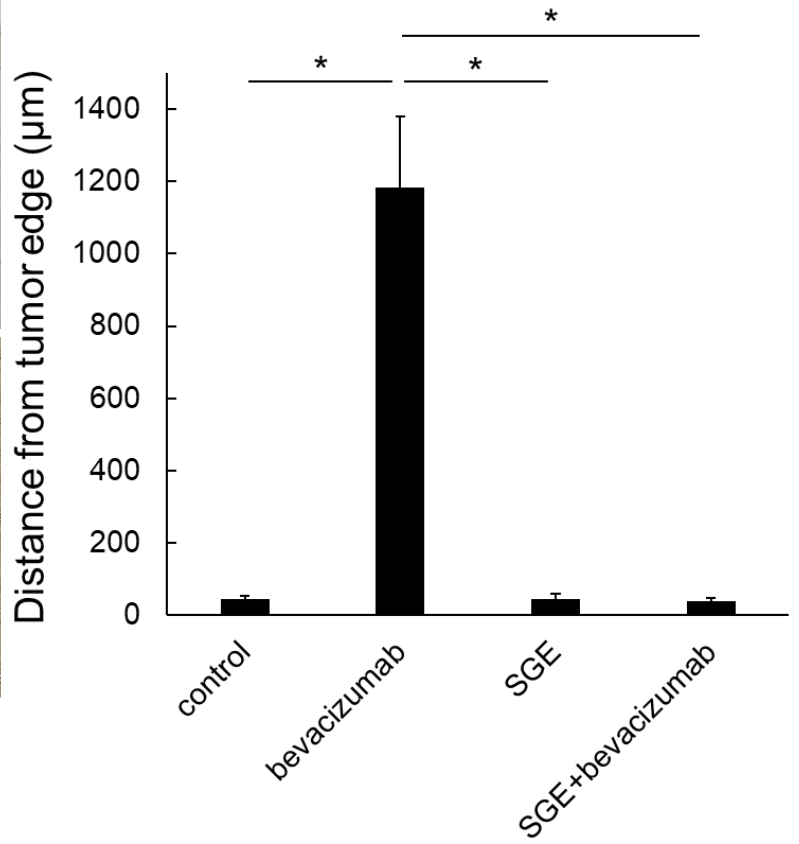


Table 1A Pathway statistics: G1_SGE_vs_control, Fold Change > 4

\begin{tabular}{|l|l|l|}
\hline Pathway & Criterion for Z score [z] & Permuted P-Value [p] \\
\hline Notch Signaling Pathway & 3.23 & 0.004 \\
\hline Dopaminergic Neurogenesis & 2.97 & 0.008 \\
\hline IL-2 Signaling Pathway & 2.8 & 0.009 \\
\hline $\begin{array}{l}\text { GPCRs, Class C Metabotropic } \\
\text { glutamate, pheromone }\end{array}$ & 2.7 & 0.013 \\
\hline Adipogenesis genes & 2.61 & 0.01 \\
\hline TYROBP Causal Network & 2.52 & 0.019 \\
\hline SIDS Susceptibility Pathways & 2.37 & 0.017 \\
\hline Retinol metabolism & 2.35 & 0.011 \\
\hline Neural Crest Differentiation & 2.32 & 0.009 \\
\hline Leptin Insulin Overlap & 2.3 & 0.017 \\
\hline TNF-alpha NF-kB Signaling Pathway & 2.11 & 0.035 \\
\hline Delta-Notch Signaling Pathway & 1.99 & 0.034 \\
\hline Heart Development & 1.97 & 0.039 \\
\hline IL-7 Signaling Pathway & 1.97 & 0.032 \\
\hline
\end{tabular}


Table 1B Pathway statistics: G1_SGE_vs_control, Fold Change < -4

\begin{tabular}{|c|c|c|}
\hline Pathway & Criterion for $\mathrm{Z}$ score $[\mathrm{z}]$ & Permuted P-Value [p] \\
\hline Cytoplasmic Ribosomal Proteins & 11.93 & 0 \\
\hline mRNA processing & 9.17 & 0 \\
\hline Electron Transport Chain & 7.43 & 0 \\
\hline Translation Factors & 6.4 & 0 \\
\hline Oxidative phosphorylation & 5.3 & 0 \\
\hline Proteasome Degradation & 5.16 & 0 \\
\hline Exercise-induced Circadian Regulation & 4.46 & 0 \\
\hline $\begin{array}{l}\text { Splicing factor NOVA regulated synaptic } \\
\text { proteins }\end{array}$ & 4.43 & 0 \\
\hline Glycolysis and Gluconeogenesis & 3.82 & 0 \\
\hline TNF-alpha NF-kB Signaling Pathway & 3.79 & 0 \\
\hline Mitochondrial Gene Expression & 3.56 & 0 \\
\hline TCA Cycle & 3.51 & 0 \\
\hline Wnt Signaling Pathway NetPath & 3.48 & 0 \\
\hline G Protein Signaling Pathways & 3.45 & 0 \\
\hline $\begin{array}{l}\text { Myometrial Relaxation and Contraction } \\
\text { Pathways }\end{array}$ & 3.28 & 0.002 \\
\hline EGFR1 Signaling Pathway & 2.92 & 0.001 \\
\hline G13 Signaling Pathway & 2.48 & 0.012 \\
\hline Calcium Regulation in the Cardiac Cell & 2.46 & 0.012 \\
\hline Hypothetical Network for Drug Addiction & 2.29 & 0.017 \\
\hline IL-3 Signaling Pathway & 2.13 & 0.029 \\
\hline MAPK signaling pathway & 2.03 & 0.041 \\
\hline NLR Proteins & 1.94 & 0.034 \\
\hline Oxidative Stress & 1.9 & 0.046 \\
\hline MAPK Cascade & 1.9 & 0.047 \\
\hline
\end{tabular}


Table 2A Pathway statistics: G3_SGE+BEV_vs_SGE, Fold Change $>4$

\begin{tabular}{|l|l|l|}
\hline Pathway & Criterion for Z score [z] & Permuted P-Value [p] \\
\hline Cytoplasmic Ribosomal Proteins & 17.89 & 0 \\
\hline mRNA processing & 8.25 & 0 \\
\hline Translation Factors & 7.34 & 0 \\
\hline Exercise-induced Circadian Regulation & 5.17 & 0 \\
\hline Proteasome Degradation & 4.96 & 0 \\
\hline TNF-alpha NF-kB Signaling Pathway & 3.76 & 0 \\
\hline Electron Transport Chain & 3.24 & 0 \\
\hline Oxidative phosphorylation & 2.78 & 0.007 \\
\hline Glycogen Metabolism & 2.48 & 0.013 \\
\hline Hypertrophy Model & 2.38 & 0.018 \\
\hline Delta-Notch Signaling Pathway & 2.23 & 0.02 \\
\hline PluriNetWork & 2.14 & 0.044 \\
\hline
\end{tabular}


Table 2B Pathway statistics: G3_SGE+BEV_vs_SGE, Fold Change <- 4

\begin{tabular}{|l|l|l|}
\hline Pathway & $\begin{array}{l}\text { Criterion for Z } \\
\text { score }[\mathrm{z}]\end{array}$ & Permuted P-Value [p] \\
\hline Glucocorticoid \& Mineralcorticoid Metabolism & 3.33 & 0.006 \\
\hline Polyol pathway & 3.18 & 0.023 \\
\hline Robo4 and VEGF Signaling Pathways Crosstalk & 2.48 & 0.036 \\
\hline TNF-alpha NF-kB Signaling Pathway & 2.19 & 0.012 \\
\hline ACE Inhibitor Pathway & 2.04 & 0.022 \\
\hline TGF Beta Signaling Pathway & 1.84 & 0.061 \\
\hline Ptf1a related regulatory pathway & 1.61 & 0.04 \\
\hline
\end{tabular}


Figure 1
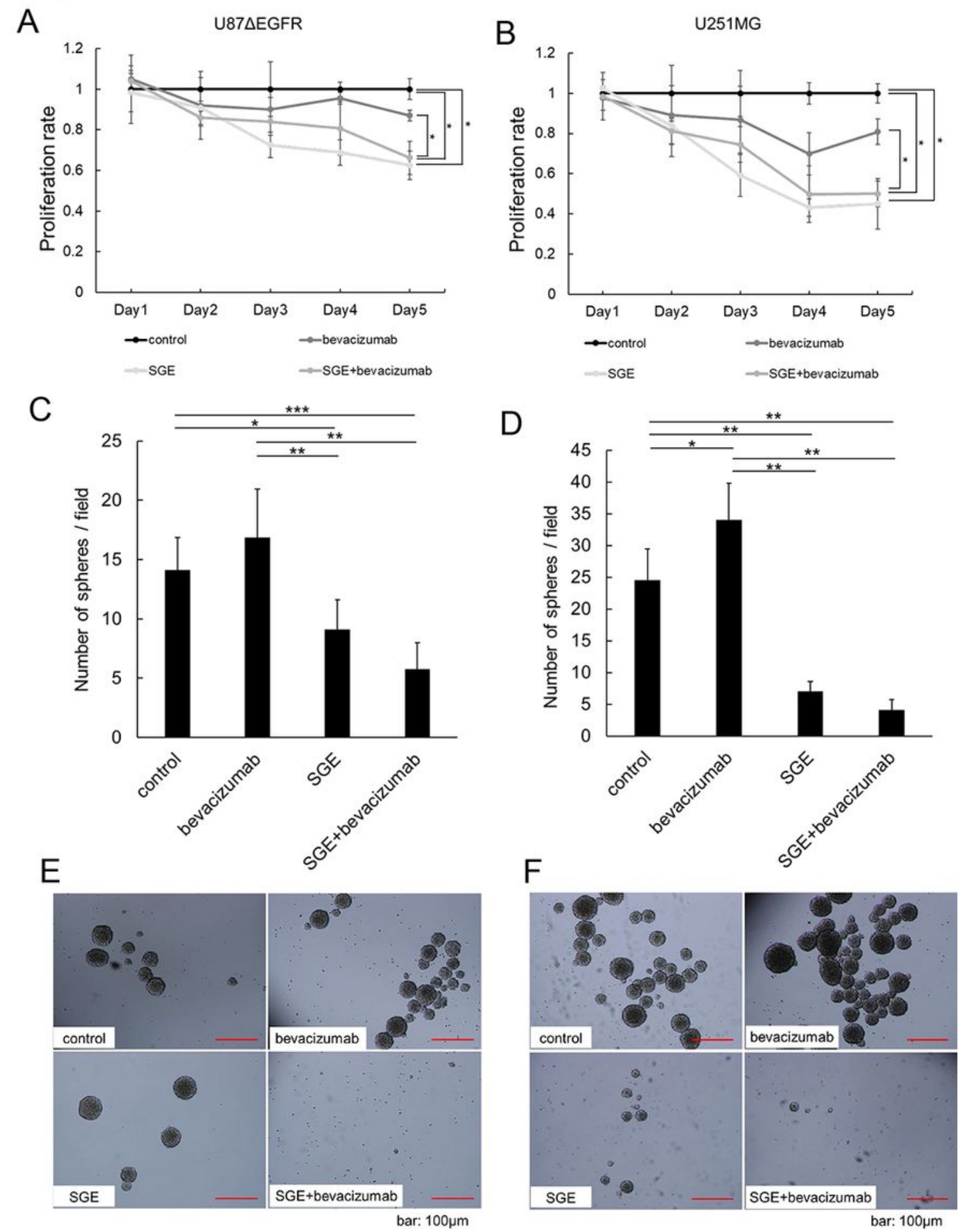

\section{Figure 1}

Cytotoxic effect of Ad-SGE-REIC, bevacizumab, and the combination on glioma cell lines. U87 $\triangle$ EGFR (A) and U251MG (B) glioma cells were treated with saline as control or bevacizumab $(1 \mathrm{mg} / \mathrm{ml})$ and infected with saline or Ad-SGE-REIC (SGE; MOI of 30). Cell viability was examined every $24 \mathrm{~h}$ after infection. Data 
shown are the proportion of viable cells relative to control cells. Values are the mean \pm SEM from five independent experiments. Statistical significance was calculated by analysis of variance with one-way ANOVA with Tukey's post hoc test. (C), (D) The number of spheres formed from 104 cells were counted. Data are expressed as mean \pm SD from three independent experiments. $(E, F)$ Representative images from the sphere formation assay (C, E: MGG8 cells, D, F: MGG23 cells). ${ }^{*} p<0.05,{ }^{*} p<0.01$ and ${ }^{* \star *} p<0.001$ compared with the indicated groups.

\section{Figure 2}
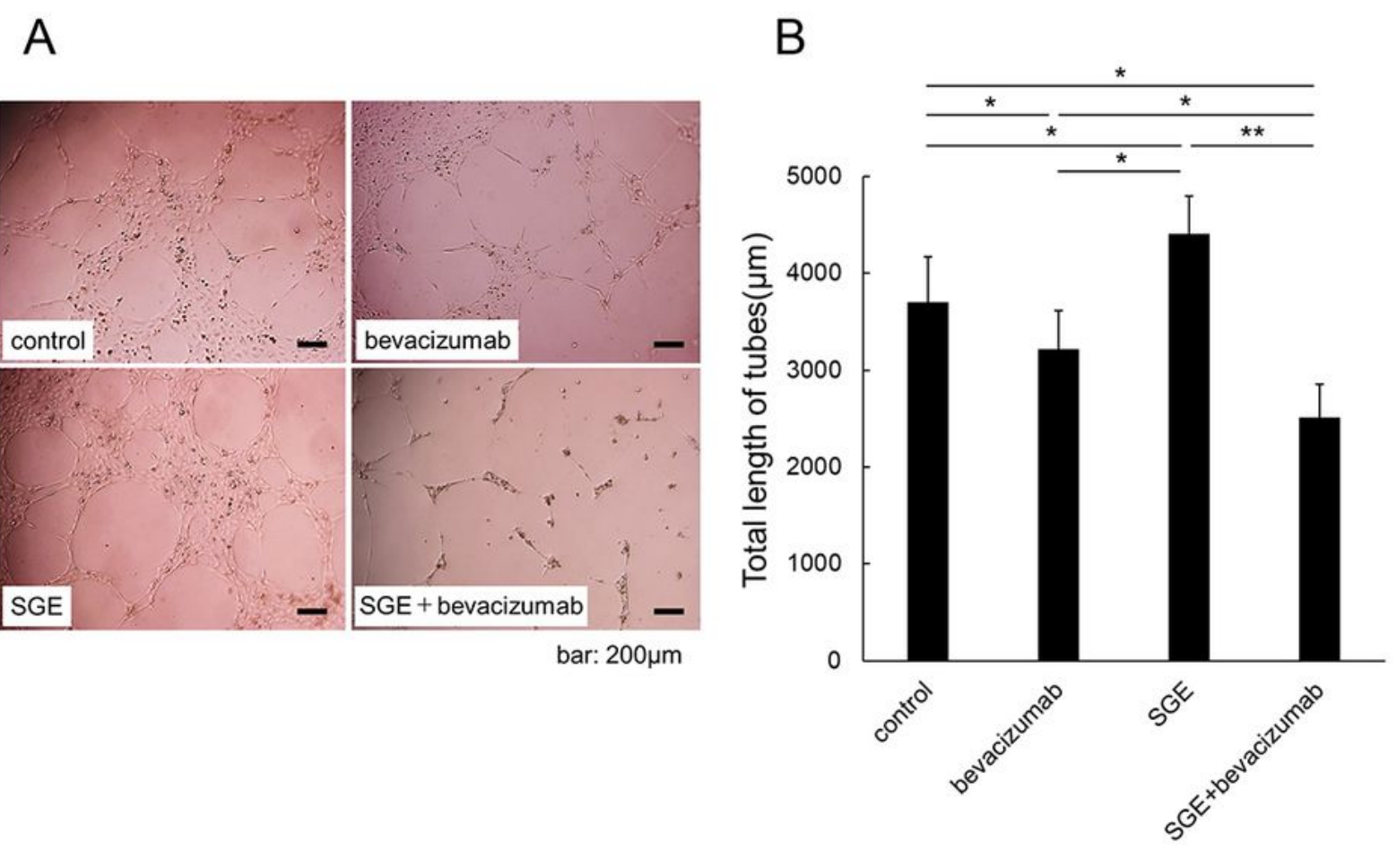

\section{C}
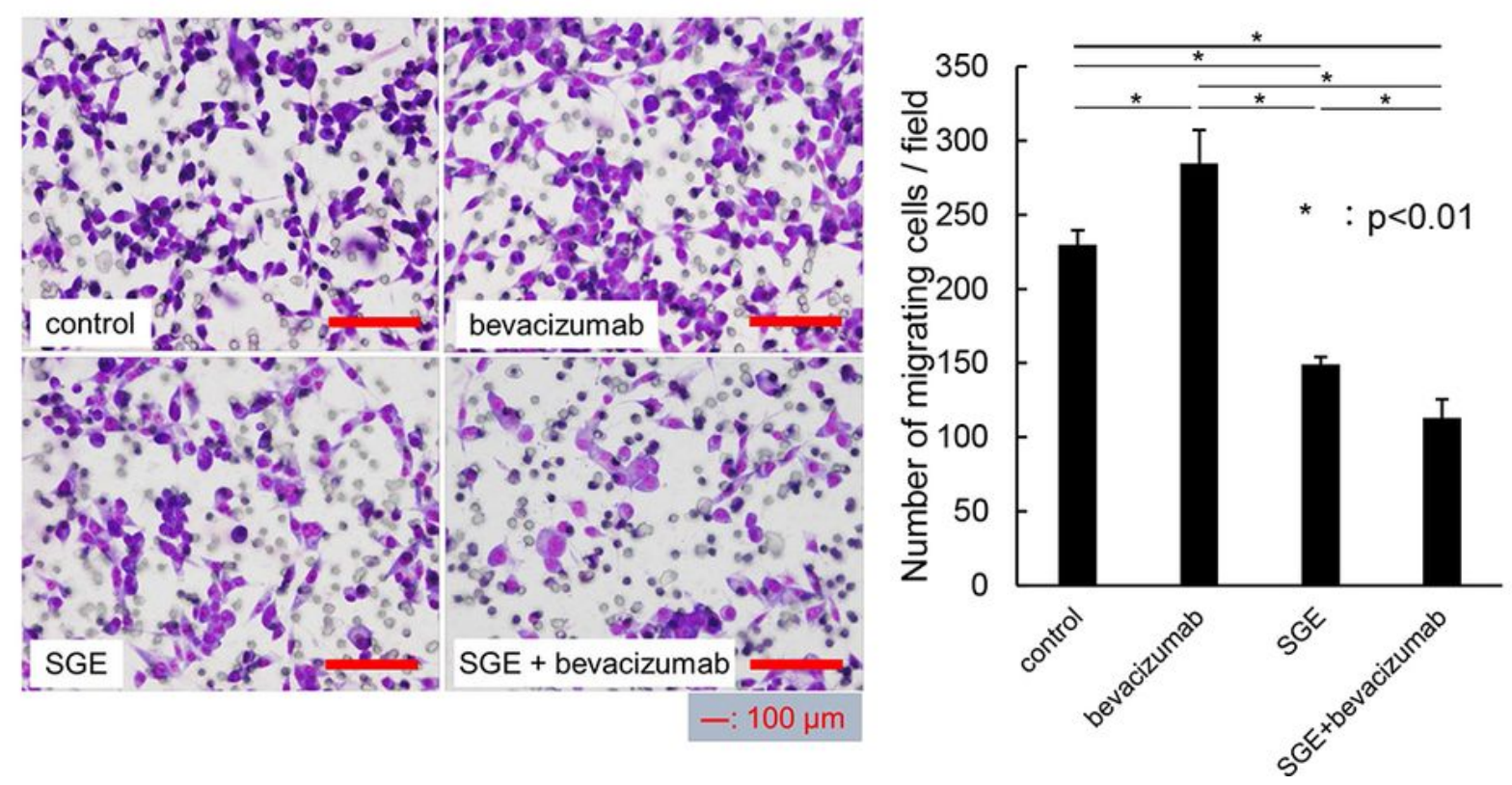

Figure 2 
Inhibition of endothelial cell tube formation. Human umbilical vein endothelial cells (HUVECs) were treated with medium containing vascular endothelial growth factor (VEGF)-A along with Ad-SGE-REIC and/or bevacizumab and then assayed by the KURABO Angiogenesis Kit. (A) Representative images of tube formation of HUVECs. Control: VEGF-A (10ng/ml); SGE: VEGF-A/Ad-SGE-REIC (5x102pfu); bevacizumab: VEGF-bevacizumab (0.1 mM); and SGE+bevacizumab: VEGF-A/ Ad-SGE-REIC/ bevacizumab. (B) Significant reduction in tube formation of HUVECs treated with Ad-SGE-REIC and bevacizumab combined compared with Ad-SGE-REIC or bevacizumab monotherapy $\left({ }^{*} \mathrm{p}<0.0090\right.$; ${ }^{* \star} p<0.028$ ). (C) Representative images from the two-chamber invasion assay. Glioma cell lines were incubated with conditioned medium (CM) derived from glioma cells treated with Ad-SGE-REIC. Cells were treated with bevacizumab. (D) Invading cells were counted $24 \mathrm{~h}$ after treatment. Data shown are the number of invading cells relative to those treated with saline as a control. Data shown are the proportions of invading distance against core diameter relative to those treated with saline as a control. Values are the mean \pm SEM from five independent experiments. Statistical significance was calculated by analysis of one-way ANOVA with Tukey's post hoc test. ${ }^{*} p<0.05$, ${ }^{* *} p<0.01$ and ${ }^{* \star *} p<0.001$ compared with the indicated groups. 
Figure 3

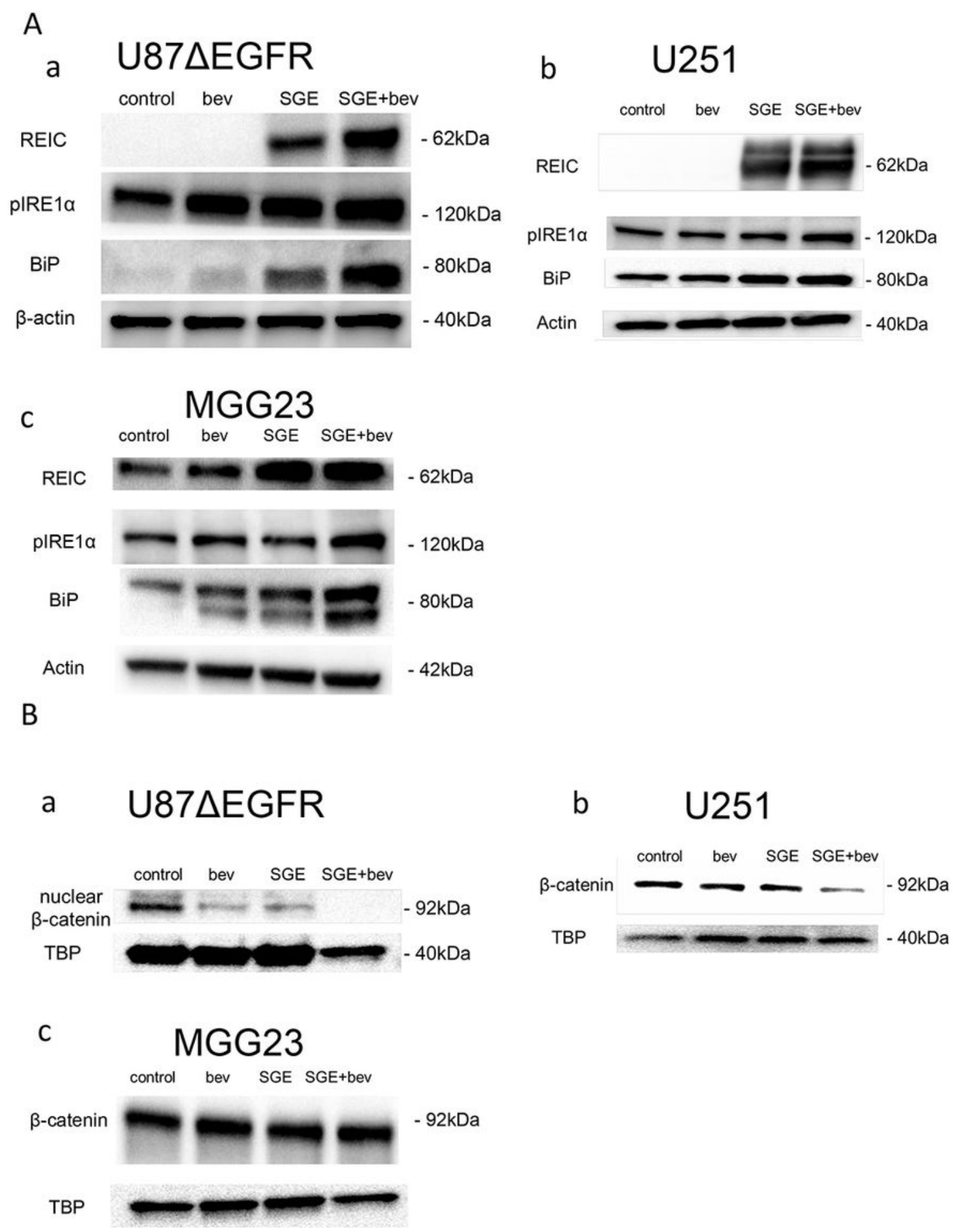

\section{Figure 3}

ER stress in U87 $\triangle$ EGFR glioma cells after treatment with Ad-SGE-REIC. U87 $\triangle E G F R$ cells were infected with Ad-SGE-REIC at a MOI of 10. Immunoblot analysis showed that levels of REIC, BiP, and

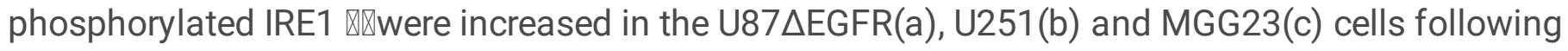
treatment with Ad-SGE-REIC. Moreover, higher amount of protein levels showed in combination treatment. (B) U87 $\triangle E G F R$ cells were infected with Ad-SGE-REIC at an MOI of 10, or treated with bevacizumab or 
combination. A reduction in $\beta$-catenin expression occurred in parallel with increased expression of REIC/Dkk-3 ( $n=4)$. Moreover, less amount of protein levels showed in combination treatment.

Figure 4

A

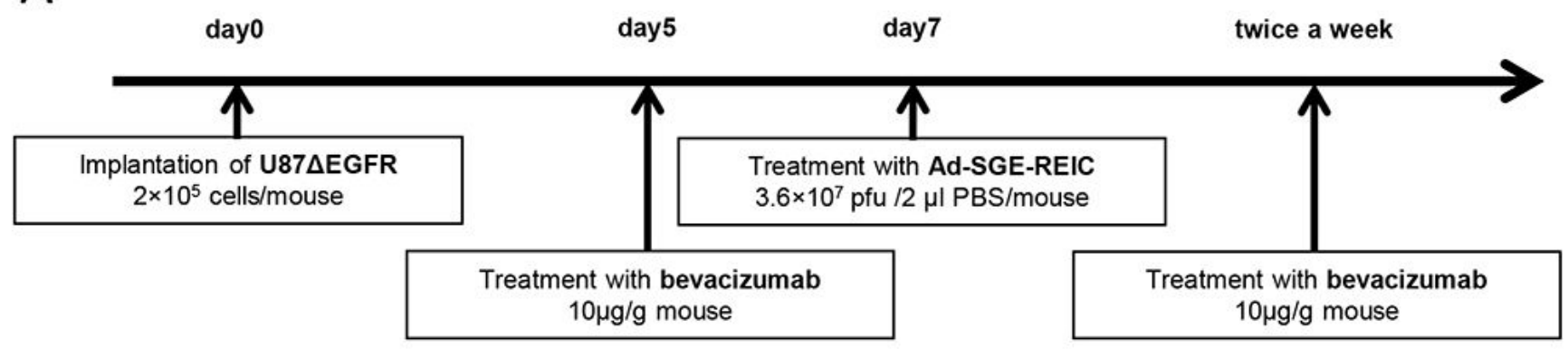

B

\section{Overall survival}

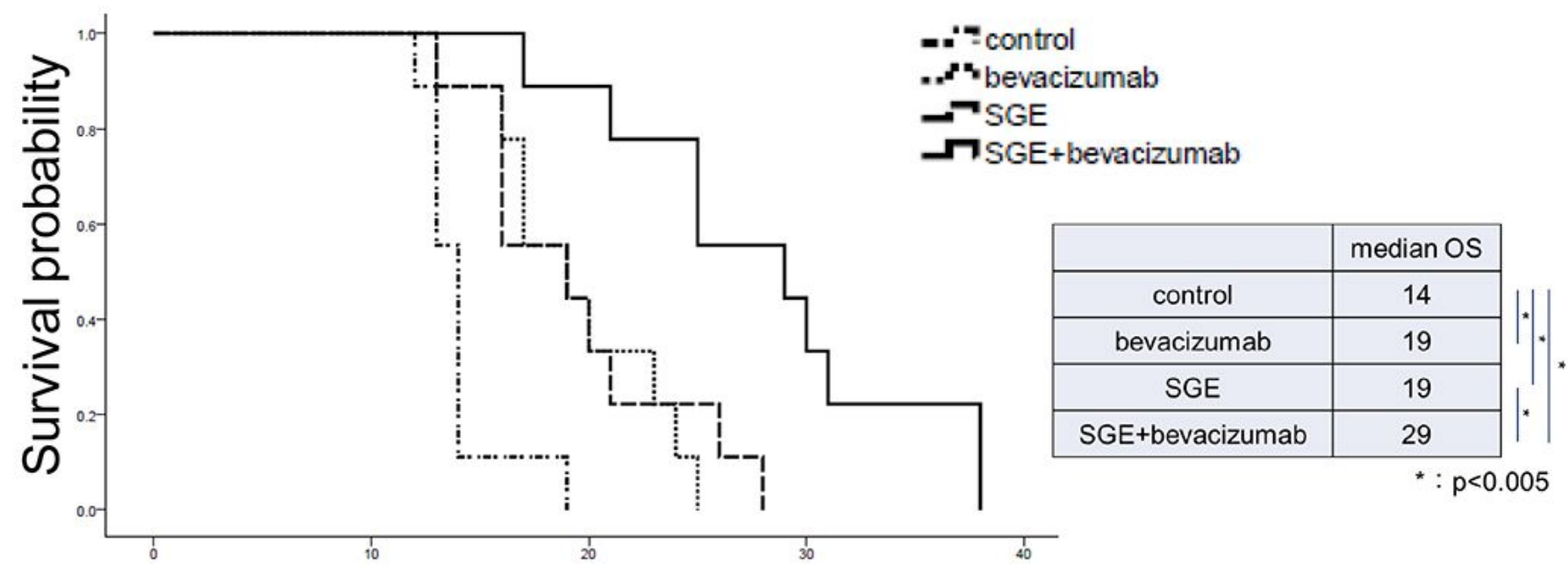

Figure 4

Kaplan-Meier survival curves and histological analysis of mice implanted with intracranial U87 $\triangle E G F R$ glioma cells. (A) Glioma cell-bearing animals were administered saline or bevacizumab intraperitonially on the indicated days and intratumoral saline or virus on day 7. (B) Athymic nude mice bearing intracranial U87 $\triangle$ EGFR gliomas were treated with $3.6 \times 107$ pfu Ad-SGE-REIC, and bevacizumab was administered intraperitoneally at $10 \mu \mathrm{g} / \mathrm{g}$. Statistical significance was calculated by the log-rank test. 


\section{Figure 5}

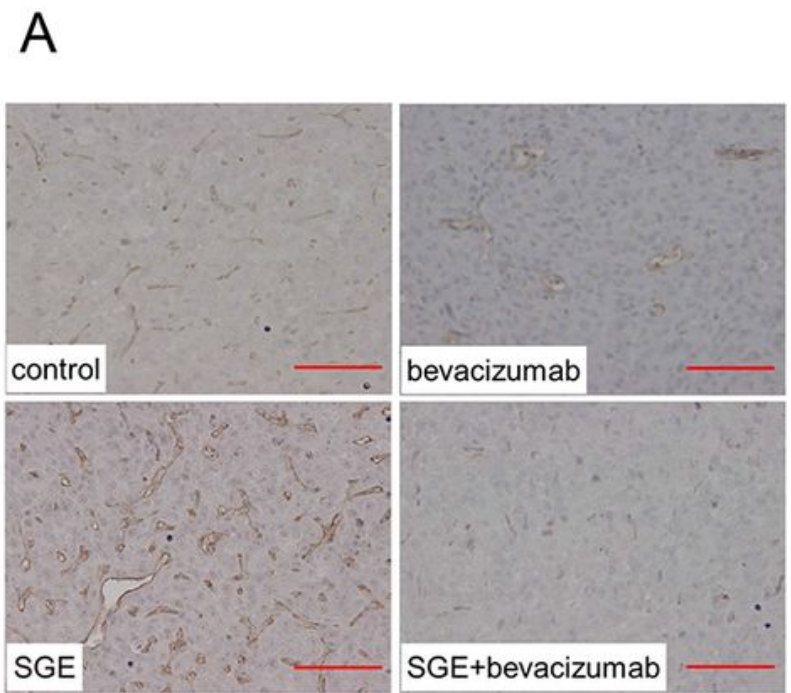

bar: $100 \mu \mathrm{m}$
B

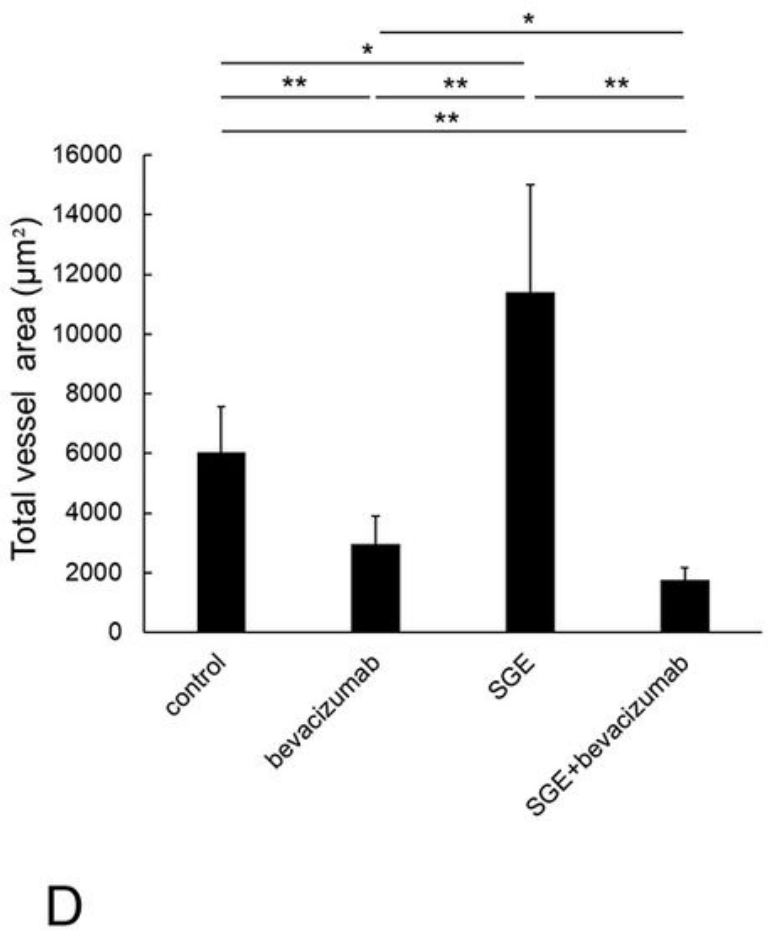

C
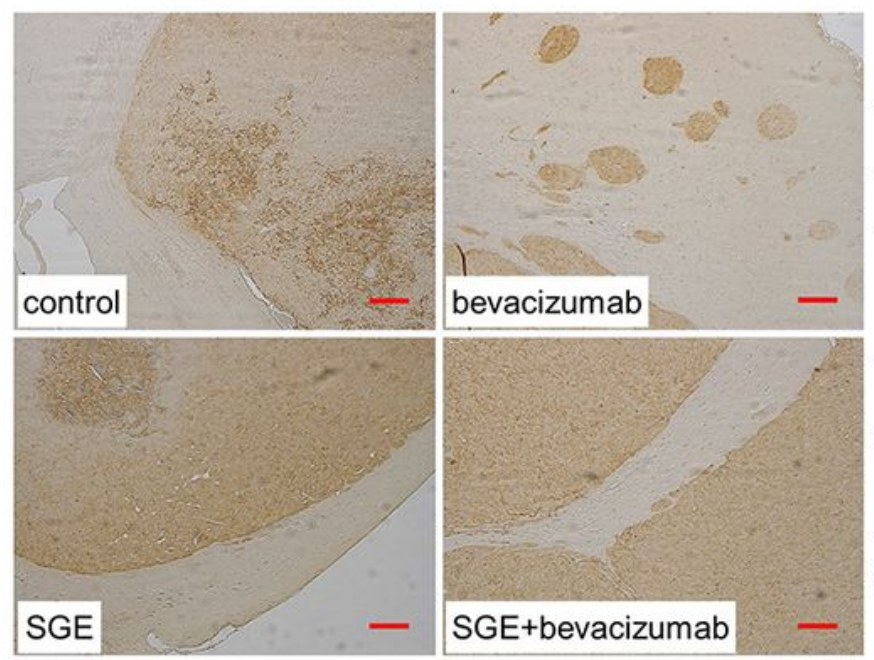

bar: $200 \mu \mathrm{m}$

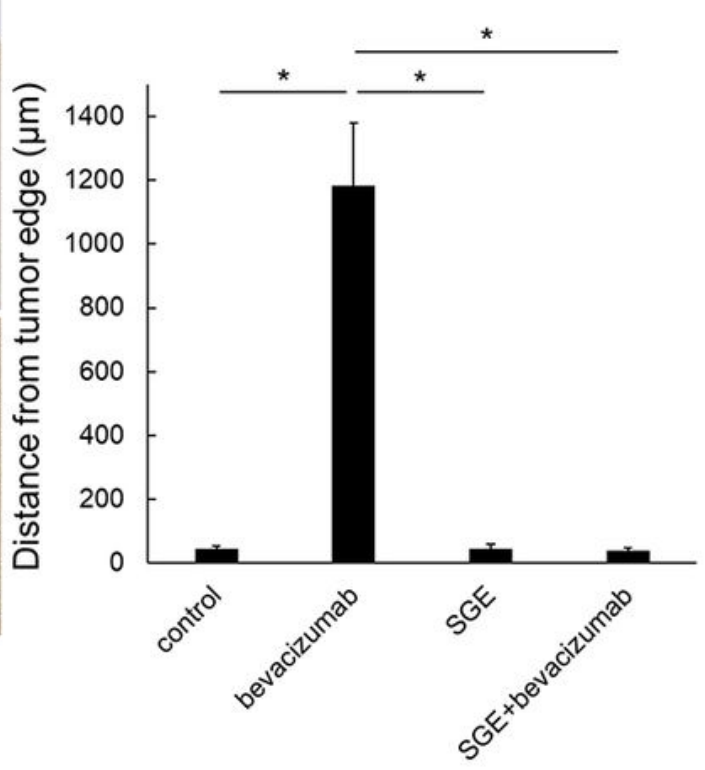

\section{Figure 5}

Anti-angiogenic effect of bevacizumab. (A) Tumor vessels were identified with CD31. Untreated U87 $\triangle E$ EFR orthotopic tumor was observed with angiogenic growth. (B) Reduction of tumor vessels with bevacizumab therapy. Bevacizumab significantly decreased vessel density of tumors; the vessel density of the Ad-SGE-REIC-treated group was significantly increased compared with the control. In the combination treatment of Ad-SGE-REIC with bevacizumab, the vessel density was significantly decreased 
compared with Ad-SGE-REIC single treatment. (C) Immunohistochemical staining of the tumors with antihuman leukocyte antigen monoclonal antibody. The untreated tumor shows the expansion of the tumor with well-defined borders. (D) After treatment with bevacizumab, the tumor border became irregular with tumor invasion. ${ }^{*} p<0.01$. The invasiveness was assessed by the distance between the tumor mass edge and invasive lesion. Values are the mean \pm SEM from five independent experiments. Statistical significance was calculated by analysis of one-way ANOVA with Tukey's post hoc test.

\section{Supplementary Files}

This is a list of supplementary files associated with this preprint. Click to download.

- Supplementaryinformation.pdf 